\title{
LA REFORMA DEL PROCEDIMIENTO DE REFORMA CONSTITUCIONAL EN ESPAÑA
}

JOSÉ MANUEL VERA SANTOS 
SUMARIO

INTRODUCCIÓN: EL AMO DE CASA SE ENCUENTRA VALORANDO LA POSIBILIDAD DE REALIZAR REFORMAS EN LA COCINA. 1. EL TÍTULO X DE LA CONSTITUCIÓN ESPAÑOLA DE 1978. 1.1 La iniciativa para la reforma constitucional y sus límites temporales (arts. 166 y 169). 1.2 El procedimiento de reforma recogido en el artículo 167. 1.3 El procedimiento de reforma del artículo 168. 2. POSIBLES Y DESEABLES REFORMAS, O COMO EL SUEÑO DE LA RAZÓN PUEDE, AUNQUE NO DEBE, PRODUCIR MONSTRUOS. 2.1 Reflexiones previas. 2.2 En cuanto a la iniciativa en ambos procedimientos. 2.3 Referidas a las previsiones recogidas en el artículo 167.2. 4 Referidas a las previsiones recogidas en el artículo 168. 3 PROPUESTAS QUE SE PLANTEAN. 


\title{
LA REFORMA DEL PROCEDIMIENTO DE REFORMA CONSTITUCIONAL EN ESPAÑA
}

\author{
JOSÉ MANUEL VERA SANTOS ${ }^{1}$ \\ Catedrático de Derecho constitucional \\ Universidad Rey Juan Carlos
}

\section{INTRODUCCIÓN: EL AMO DE CASA SE ENCUENTRA VALORANDO LA POSIBILIDAD DE REALIZAR REFORMAS EN LA COCINA}

Aunque he participado, con mucho gusto por cierto, en algún volumen colectivo que estudia la tan traída y llevada reforma constitucional ${ }^{2}$, y de mis propias obras anteriores se pueden inferir cuestiones variadas en las que mi pos-

\footnotetext{
${ }^{1}$ Departamento de Derecho Público I y Ciencia Política. Facultad de Ciencias Jurídicas y Sociales Universidad Rey Juan Carlos. Paseo de los Artilleros s/n. 28032 Madrid. Correo electrónico: josemanuel.vera@urjc.es. Concluido ya este artículo, he conocido el fallecimiento de D. Pedro de Vega García, maestro de maestros. La casualidad ha querido que esta aportación versara sobre una temática «muy suya», ya que su monografía de 1985 La reforma de la Constitución y la problemática del poder constituyente, publicada por la editorial Tecnos, es una de las bases para el estudio posterior de la cuestión. Coincidí con él en varias ocasiones, le invité a enseñarnos en el Centro de Estudios «Ramón Carande»... compartí con él un tribunal de oposiciones en la Universidad de León, y hasta me atreví a volver con él ¡en coche Aparte de muchas otras anécdotas y enseñanzas, se me quedó grabada una que siempre he intentado llevar a la práctica. Escrita en latín impacta más: in claris non fit interpretatio. Él concluía después insistiendo en que los argumentos rocambolescos siempre escondían algo. Y no era bueno. Y lo extendía a la necesaria claridad argumental en los escritos doctrinales, abominando del estudioso que no era capaz de transmitir sus argumentos con hilazón meridiana, posibilitando su entendimiento por sus lectores. Que descanse en paz.

${ }^{2}$ Me refiero a García RocA, F. J. (et alii) Pautas para una reforma constitucional. Informe para el debate. Navarra: Thomson Reuters Aranzadi, 2014.
} 
tura es crítica con la regulación jurídico política actual ${ }^{3}$, tengo que reconocer que estoy cansado, académica y cívicamente, de oír el mantra de que «hay que reformar la Constitución», como si dicha reforma supusiese el principio y el fin, el alfa y la omega, que solucionara las deficiencias cívicas y sociales, individuales y colectivas, de la sociedad española. Nos encontramos, en fin, ante un nuevo capítulo de la milagrera tendencia española consistente en que cambiando la/de Constitución se acaba el problema convivencial, falsa taumaturgia que tanto mal nos ha traído al constitucionalismo patrio ${ }^{4}$.

Refiriéndome al tema objeto de estudio, y en relación con el título de este epígrafe introductorio, tengo que indicar que, cuando muy joven leía el manual de los profesores De Esteban y González-Trevijano, una frase se me quedó grabada, bien que no era, y sigue sin serlo, "políticamente correcta»: «Ciertamente, como ha señalado George Vedel, preguntar a un constitucionalista sobre las reformas necesarias de una Constitución, es lo mismo que preguntar a una ama de casa sobre las reformas necesarias de su cocina... $\gg^{5}$. Esta cita evidencia, por supuesto, la tendencia natural del estudioso del asunto público para construir crítica teórica. Pero ésta, incluida la propia, debe teleológicamente vincularse al servicio de la convivencia social y no a una mal entendida diferenciación intelectual dentro de la academia.

Soy consciente de la imperfección de cualquier sistema democrático y, por ende, de su norma básica, que tal es la Constitución; pero discrepaba, y discrepo, de esa teoría simplista en virtud de la cual nuestra Carta Magna fuera, ayer, protagonista absoluta de todas las virtudes, como tampoco lo es, hoy, de todos los defectos de la poliédrica realidad jurídica y política patria ${ }^{6}$.

${ }^{3}$ Como he reflejado en reiteradas ocasiones en mis aportaciones doctrinales, clases, conferencias y artículos periodísticos, soy partidario de una reforma constitucional que, por ejemplo, permitiera una redefinición competencial, en favor del Estado, de materias tan relevantes como educación, sanidad o justicia. Dicho lo anterior, puedo pensar eso o todo lo contrario. Y si dicha postura no gozase del necesario consenso social y político, únicamente serviría para lo que sirven las opiniones doctrinales, que no es poco: marcar caminos que luego la sociedad, a través de sus representantes, a través de sus instituciones, puede o no transitar.

${ }^{4}$ He aludido a esta cuestión en variadas ocasiones, si bien, por todas, puede valer Vera SANTOS, J. M. Las Constituciones de España. Navarra: Thomson-Civitas, 2008, en concreto en la página 25.

5 De Esteban, J. y González-Trevijano, P. J. Tratado de Derecho constitucional III, Madrid. Facultad de Derecho de la Universidad Complutense de Madrid, 2000, pág. 748.

${ }^{6}$ Sin ningún ánimo de exhaustividad, pero recordando a los «clásicos», aparte de por respeto, por convicción teórica y académica, el estudio de la «fórmula política» a la que aludía Lucas Verdú, del «régimen político» del profesor Jiménez de Parga, además de los autores clásicos franceses como el propio Vedel, denota que tanto la realidad como la virtualidad teórica de la convivencia democrática viene dada por diferentes factores, amén del normativo. Muy interesante a este respecto se nos presenta la lectura de Ruipérez Alamillo, J. «De la reforma constitucional y sus límites materiales. Consideraciones desde la Teoría del Estado y de la Constitución», en Teoría y Realidad 
Comencemos por el principio $^{7}$, para destacar que, al tratar la reforma constitucional, nos movemos en el marco de la democracia «de» la Constitución, de la democracia constitucional $^{8}$ y que la misma se basa en un pilar básico que es el consenso 9 ,

Constitucional, n. ${ }^{\circ}$ 30, págs. 89-138, recordando las posturas existentes, dentro del estudio normativo-constitucional, entre Kelsen (págs. 111 y 112, sobre todo) y Heller (págs. 120 y 121). Ejemplifica en ambos autores los diferentes conceptos, normativo puro y valorativo, entre los que se mueve la discusión teórica desde Weimar, aplicados, primero al concepto de Constitución material y posteriormente, a la problemática de los límites materiales a la reforma constitucional. En la página 90 cita a Hesse y su asunción de las teorías de Heller y de Smend respecto a la consideración de «la Constitución del Estado como la, en la medida de lo posible, perfecta adecuación entre la realidad jurídico-normativa, que es la que se refleja en el instrumento de gobierno escrito, y la realidad política, social y económica subyacente». No vamos a abundar más, pero desde Lassalle o Bonald y las «constituciones de papel», hasta Loewenstein y su clasificación constitucional ontológica, la evidencia de que el «deber ser» normativo presenta muchas facetas, entre ellas la valorativa, como destacase también ya en los albores de nuestro constitucionalismo moderno García Pelayo, además de que la realidad política, económica o social subyacente es relevante, se nos presenta como indiscutible, mucho más en cuestiones que afectan a la reforma constitucional.

7 «Comienzo por el principio... y el principio era político: la relación entre los conceptos de poder constituyente y poder de reforma constitucional». Así titulé el apartado segundo del artículo VerA SAntos, J. M. «Sobre el Título X de la Constitución española de 1978: de la reforma constitucional», en el volumen colectivo López Guerra, L., García Ruiz, J. L. y García FernándeZ, J. Constitución y desarrollo político. Estudios en homenaje al Profesor Jorge de Esteban. Valencia: Tirant lo Blanch, 2013, págs. 1397-1433 (en concreto 1401-1403). En dichas páginas, en resumen, siguiendo al maestro DE VEGA en su clásica monografía La reforma de la Constitución y la problemática del poder constituyente (Madrid: Tecnos, 1988), destaco las concepciones estadounidense y francesa respecto a la teoría del poder constituyente y la consiguiente ubicación del mismo y su diferencia con los poderes constituidos, incluyendo el de reforma de la Constitución. No es el quid del tema objeto de estudio en este artículo, pero sí es la piedra angular de cualquiera disquisición que se realice sobre la reforma. No creo que nada se pueda escribir sin tener claro los conceptos básicos de la Teoría política y de la Teoría de la Constitución.

8 Por su claridad, cito a Aragón Reyes, M. «¿Cambiar la Constitución para adaptarla o para transformarla? Requisitos y límites de la reforma constitucional», en Teoría y Realidad Constitucional, n. ${ }^{\circ}$ 36, pág. 313-327 (315). Dice el ex Magistrado del Tribunal Constitucional: «De ahí [se refiere al archiconocido artículo 16 de la Declaración de Derechos del Hombre y del ciudadano de 1789] se deriva el concepto de democracia constitucional, que se basa en distinguir la democracia «de la constitución» de la democracia «en la constitución», o en otras palabras, la democracia de la constitución de la democracia de la ley. La primera opera en el plano del poder constituyente, y por lo mismo, en el de la reforma constitucional; la segunda en el plano del poder constituido; la primera es una democracia de consenso, y la segunda una democracia pluralista, cuya libertad de opciones políticas está constreñida al marco fijado por la constitución (...)».

9 Hace ya años escribía sobre el consenso logrado en la aprobación de la Constitución española de 1978, aludiendo al mismo como «característica esencial», y diferenciando cuatro aspectos: el consenso como valor, entendido como principio esencial, generalizable en todo caso para el logro de esa democracia constitucional, sea en el país que sea; el consenso como elemento necesario, que aplicado al caso español venía dado por el previo reparto electoral de escaños a las diferente fuerzas políticas, que hacía «obligado» el acuerdo; el consenso como procedimiento, es decir, el análisis formal del 
ingrediente básico a la hora de trasmutar las consideraciones teóricas, individuales o grupales, a la práctica de la normativa a aprobar en aras del logro del interés general.

Incido en esta aportación en una temática que ya he estudiado con antelación, bien que desde ópticas diferentes ${ }^{10}$ : la posible y deseable (o no) reforma del propio proceso establecido en el Título $\mathrm{X}$ de la Constitución, tantas veces utilizado como excusa de un imposible encauzamiento de las reformas sugeridas por unos y por otros... ${ }^{11}$ Desde ahora advierto que tan denostada normativa no constituye un ejemplo descatalogado dentro de la taxonomía del constitucionalismo democrático ${ }^{12}$.

proceso concreto seguido (no parece muy de «consenso», por ejemplo, presentar formalmente temáticas complejas para acordar sobre ellas, sin antes avisar de ello y elaborar un estudio previo); concluía aludiendo al consenso como realidad alcanzada, fin último de los pactos, es decir, que el consenso se refleje en los artículos constitucionales. Lo mismo ha de destacarse ahora, no tanto respecto al momento constituyente sino también en lo referente a la reforma constitucional para que la misma no «rompa» la Constitución de todos, para que nos encontremos ante una reforma constitucional y no frente a un cambio de Constitución (Merino Merchán, J. F; Pérez-Ugena Coromina, M. y Vera Santos, J. M. Lecciones de Derecho constitucional. Madrid: Tecnos, 1995, págs... 112 a 114). Comparto la reflexión de Gavara DE CARA, J. C ( «Encuesta» realizada por la revista Teoría y Realidad Constitucional, n. ${ }^{\circ} 29,2012$ pág. 23), respecto de la dificultad que entraña alcanzar, expresaría yo, «el consenso después de consenso»:»Las palabras mágicas «consenso constitucional» han sido fruto de un verdadero dilema del prisionero, ya que mediante el acuerdo todos los partidos políticos se incluyeron en su momento en la casilla del gana-gana, es decir, cedían en parte todos para obtener un beneficio común considerablemente más grande, existiendo, en consecuencia, incentivos para la cooperación y adquiriendo el texto constitucional una posición de centralidad desde el punto de vista de las aspiraciones de los partidos políticos (...) Sin embargo, en el futuro cualquier modificación implicará que alguno de los sujetos pierda, ya que la modificación hará mover dicho punto de centralidad hacia una posición política diferente, más alejada de los respectivos planteamientos (...)». Amén.

${ }^{10}$ Me refiero a esta temática en Vera Santos, J. M. La reforma constitucional en España. Madrid: La Ley, 2007 (sobre todo págs. 169 y ss.); también en Vera Santos, «Sobre el Título X de la Constitución...», o. c., págs. 1397-1433. En ninguna de estas obras incido en la posible reforma del procedimiento estudiado, bien que de mis argumentaciones generales se derivan, en pura lógica académica e intelectual, las consideraciones que en este artículo se concretizan.

${ }^{11}$ Contreras Casado, M., en la «Encuesta» citada, pág. 16, indica: «coincido en este punto con quienes afirman que los problemas de un planteamiento reformista sobre la Constitución española hay que buscarlos fuera del Título X». La utilización bastarda del procedimiento de reforma constitucional como causa de la imposibilidad de las reformas propuestas también fue usada en la Segunda República española, como indico en Vera SANTOS, J. M. La reforma ... o. c., págs. 133-134 y reitero en «No es eso, no es eso... La Constitución española de 1931», en Libro Homenaje a Armando Torrent. Madrid: Dykinson, 2016, págs. 1283-1306 (en concreto 1290 y 1301). Vid. igualmente más adelante nota 72 , en la que aludo a la normativa concreta. No es cierto en modo alguno que la regulación constitucional del procedimiento de reforma sea la culpable del escasísimo número de reformas acaecidas hasta la fecha en nuestro país. Tanto la propia composición de los diferentes parlamentos democráticos, como también los ejemplos de regulaciones foráneas similares a la nuestra avalan mi postura.

12 López Basaguren, A, en la meritada «Encuesta», citada en nota anterior (págs. 33 y 34), resume clarificando la cuestión: «La primera sensación que me sigue trasmitiendo el Título X cada 
A efectos de discernir sobre posibles cambios a emprender en el procedimiento de reforma constitucional, primero vamos a estudiar la normativa actual para, después de diseccionada, proponer aquellos que considero más adecuados. Sin más, voy a ello.

\section{EL TÍTULO X DE LA CONSTITUCIÓN ESPAÑOLA DE 1978}

\subsection{La iniciativa para la reforma constitucional y sus limites temporales (arts. 166 y 169)}

La Constitución española, en su artículo 166, prescribe: «La iniciativa de reforma constitucional se ejercerá en los términos previstos en los apartados 1 y 2 del artículo 87».

vez que lo leo es la de ser excesivamente complicado y rígido (...) Sin embargo, creo que un análisis detenido de su significado obliga a matizar mucho — si no a modificar- esta primera impresión» A continuación indica, sobre todo referido al 168, que «la mayoría exigida, por tanto, no me parece fácilmente objetable», siempre para lograr un amplio consenso, como indica antes. Sí destaca, las dificultades añadidas al procedimiento que suponen tanto la disolución de las Cámaras como el sometimiento al referéndum (pág. 34), si bien incide en que «tanto uno como otro requisito tienen una relativamente amplia tradición en nuestro entorno, lo que quiere decir que parecen tener algún sentido. Pero uno y otro requisito no suelen darse simultáneamente (...)». Aragón Reyes (o. c., pág. 326) incide en el mismo tema: «En tal sentido, los requisitos de mayorías reforzadas de las cámaras, incluso de dos tercios o tres cuartos, la necesidad de pronunciamiento en dos legislaturas sucesivas, la realización de referéndum, etc. No pienso que puedan considerarse exageradas, sobre todo en aquellos ordenamientos en los que no existen cláusulas de intangibilidad constitucional». Así pues, los principios generales y la normativa concreta respecto a la reforma recogidos en el Titulo X son homologables al resto de ordenamientos democráticos Otra cuestión sería si son adecuadas a la realidad política española, si deben coincidir o, incluso, si la llamada al referéndum obligatorio puede influir en la argumentación defendida. Respecto a los ejemplos de derecho comparado vid. Vera Santos, La reforma, o. c., págs. 171-199. Dejando aparte el estudio de las normativas en las que la rigidez constitucional viene dada por el protagonismo de órganos diferentes a los constituidos, y aludiendo a los procedimientos solicitados constitucionalmente para la consecución de aquella, diferencio en esta obra entre a) modelos en los que prevalece la necesidad de alcanzar una mayoría cualificada (casos de Alemania y Francia); b) aquellos que, además de dicha mayoría, requieren de la aprobación de la reforma a través de dos lecturas consecutivas (Italia); c) Bélgica y Holanda, por ejemplo, abogan por la necesidad de la aprobación por dos legislaturas consecutivas. Especial incidencia debo hacer en este último caso, el de la doble legislatura, debido a ser el ejemplo que sirve a lo regulado en el artículo 168 CE, causa por la que destaco el artículo de Amérigo ALONSO, J. y Jeréz CALderón, J. J. «El procedimiento de revisión constitucional en dos legislaturas: un análisis comparado e histórico», en Revista Española de Derecho Constitucional, n. ${ }^{\circ}$ 76, 2006, págs. 179-200. Dichos autores incluyen en ese grupo «asimilable» al procedimiento recogido en el artículo 168 CE otros países, además de Bélgica y Holanda, como son Dinamarca, Estonia, Finlandia, Noruega o Suecia, bien que cada uno de ellos tengan, obviamente, sus peculiaridades procedimentales. 
Por su parte, el artículo 87 indica: «1. La iniciativa legislativa corresponde al Gobierno, al Congreso y al Senado, de acuerdo con la Constitución y los Reglamentos de las Cámaras ${ }^{13}$. 2. Las Asambleas de las Comunidades Autónomas podrán solicitar del Gobierno la adopción de un proyecto de ley o remitir a la Mesa del Congreso una proposición de ley, delegando ante dicha Cámara un máximo de tres miembros de la Asamblea encargados de su defensa. 3. Una ley orgánica ${ }^{14}$ regulará las formas de ejercicio y requisitos de la iniciativa popular para la presentación de proposiciones de ley. En todo caso se exigirán no menos de 500.000 firmas acreditadas. No procederá dicha iniciativa en materias propias de ley orgánica, tributarias o de carácter internacional, ni en lo relativo a la prerrogativa de gracia.»

Así pues, de una interpretación tanto literal como sistemática, con la exclusión explícita del apartado tercero del último de los artículos citados, los órganos dotados de iniciativa para la reforma constitucional son las Cámaras legislativas nacionales y el Gobierno, así como, de manera evidentemente secundaria, las Asambleas legislativas de las Comunidades Autónomas, resultando excluida la iniciativa legislativa popular.

Pueden destacarse al respecto tres consideraciones. En primer lugar, la existencia de un número abierto de sujetos legitimados impide la indeseable «deificación» que supondría que sólo una institución pudiera comenzar el proceso de reforma ${ }^{15}$. De igual manera, abogo por la igualdad de los sujetos legitimados para iniciar la reforma, sin atender a criterios materiales y/o procedimentales, ya que una discriminación en dicho sentido podría conllevar que, en el marco de un proceso de reforma, hubiera de volverse al iniciático momento, si se produjese a lo largo de la tramitación, un cambio referido a materias/procedimiento diferente ${ }^{16}$. Con las experiencias foráneas de mi parte, también defiendo la exclusión de la iniciativa legislativa popular como medio idóneo para comenzar el proceso de reforma ${ }^{17}$.

13 El desarrollo normativo correspondiente lo encontramos en los artículos 146 y 147 RCD y 152 a 159 RS.

${ }^{14}$ La iniciativa legislativa popular ha sido regulada mediante Ley orgánica 2/1984, reformada por Ley orgánica 4/2006.

15 Por todos, DE Vega García, o. c., págs. 128 y 130. Vid. nota 20 respecto a las concreciones de dicha iniciativa predicada de los órganos legislativos.

${ }^{16}$ En contra García Atance, M. ${ }^{a}$ V. Reforma y permanencia constitucional. Madrid: CePC, 2002, pág. 255, quien considera que sería adecuada la diferenciación de sujetos legitimados, teniendo en cuanta si el procedimiento afecta a las materias incluidas o no en el artículo $168 \mathrm{CE}$.

17 No es esta una valoración pacífica. Así, buena parte de la doctrina (por todos, DE VEGA García, La reforma..., o. c., págs. 138 y ss.; DE Esteban y GonzÁlez Trevijano, o. c., págs. 734-735; Bilbao, J. M., Rey, F. y Vidal, J. M. Lecciones de Derecho constitucional I, Valladolid: Lex Nova, 2010, pág. 291; DE OTTO, I. Derecho constitucional. Sistema de fuentes. Barcelona: 
Vayamos, pues, a estudiar la pluralidad de sujetos legitimados. Efectivamente el Gobierno puede iniciar el procedimiento de reforma constitucional con la presentación de un proyecto de reforma ${ }^{18}$, aprobado previamente en Consejo de Ministros. La propuesta que se remita al Congreso de los Diputados debe ir acompañada de una exposición de motivos y de los antecedentes necesarios para que las Cámaras puedan pronunciarse. La iniciativa gubernamental goza de preferencia o prioridad en virtud de lo dispuesto en el artículo 89 CE. Además, el Gobierno podrá retirar su proyecto de modificación de la Constitución en cualquier momento de su tramitación hasta que ya hubiese recaído acuerdo final de la Cámara sobre aquél ${ }^{19}$.

Ariel, 1999, pág. 57, se muestran a favor de que se permita la iniciativa legislativa popular en la reforma constitucional, alegando el principio de soberanía popular o la superación, en los sistemas democráticos actuales, del posible enfrentamiento entre las instituciones propias de la democracia directa y de la democracia representativa. Vid. Vera Santos, «Sobre el Título X...», o. c., págs. 1408-1410, respecto a la argumentación clásica utilizada al respecto en la discusión parlamentaria del que era artículo 159 del proyecto constitucional (que devendría en el artículo 166 CE) entre Cisneros Laborda (UCD), Fraga Iribarne (AP), Peces-Barba Martínez (PsoE) y Solé Tura (Psuc), en la sesión correspondiente de la Comisión de Asuntos Constitucionales y Libertades Públicas celebrada el 20 de junio de 1978. Creo, como argumento en el artículo citado, que sería incomprensible habilitar la iniciativa legislativa popular como instrumento para comenzar la andadura de la reforma y no permitir la misma para todo tipo de materias excluidas por la Constitución en el apartado tercero del artículo 87. Respecto a la tramitación constitucional de todo el articulado que compone el Título $\mathrm{X}$ de nuestra actual Constitución vid. Vera Santos, La reforma..., o. c. págs... 137 a 169.

18 Ya en 1987 Pérez Royo, en su obra clásica sobre la cuestión (PéRez Royo, J. La reforma de la Constitución. Madrid: Congreso de los Diputados), abogaba por que, a pesar de la literalidad del artículo 167.1 de la Constitución al aludir a «proyectos de reforma constitucional», esta norma debe ser interpretada en sentido genérico, esto es, admitiendo tanto proyectos como proposiciones de ley (pág. 161). Lo cierto es que la argumentación contraria no admitiría una mínima interpretación sistemática. En 2006 también lo reconoce el Consejo de Estado, indicando en el Informe referido a la reforma constitucional que dicha expresión «debe entenderse en su sentido más amplio, como denominación genérica comúnmente utilizada para designar los textos en los que se concretan las iniciativas normativas, con independencia de que, desde el punto de vista técnico, se trate de proyectos en sentido estricto o de proposiciones» (Rubio Llorente, F. y Álvarez Junco, M. (edits.) El informe del Consejo de Estado sobre la reforma constitucional. Texto del informe y debates académicos. Madrid: Consejo de Estado/CEPC, 2006, págs. 243-244). Por otra parte, debe señalarse, que dicho proyecto de reforma puede ser objeto de enmienda a la totalidad, lo que supondrá el consiguiente debate a la totalidad en el Pleno del Congreso de los Diputados. Una de las posibilidades será, naturalmente, la devolución del proyecto de reforma al Ejecutivo (artículos 112 y $146 \mathrm{RCD}$ ).

19 Así se deduce del artículo 129 RCD, como indica García-AtanCE, o. c., págs. 249 a 251. Con la reforma operada por la Ley orgánica 3/2004, el Consejo de Estado puede que sea solicitado para elaborar, por encargo del Gobierno, propuestas de reforma constitucional que, en puridad, 
En cuanto a las Cámaras legislativas, tanto en el caso del Congreso de los Diputados como en el del Senado, se observa un agravamiento de las mayorías para presentar la proposición de reforma constitucional, respecto a las referidas en el procedimiento legislativo ordinario. Así, una quinta parte de los diputados o dos grupos parlamentarios, en el caso de la Cámara Baja, y cincuenta miembros que no pertenezcan al mismo Grupo senatorial, pueden iniciar el proceso de reforma ${ }^{20}$.

El tercer, y plural, órgano legitimado para iniciar el proceso de reforma, son las cámaras legislativas de las Comunidades Autónomas. Esta iniciativa —que presenta una doble opción, bien se solicite la adopción del acuerdo y postrera tramitación de las meritadas asambleas ante el Gobierno o ante el Congreso de los Diputados-, la podemos calificar como subsidiaria o de segundo nivel y

deberían acompañarse como un documento más dentro de los antecedentes necesarios a los que alude la normativa. El alto órgano consultivo debe, a tal fin, atender únicamente a los objetivos, criterios y límites que el Ejecutivo le señale, aunque podrá hacer al mandante las observaciones que estime oportuno (art. 2.3). En otras palabras, en los casos de elaboración de propuestas legislativas o de reforma constitucional, el trabajo del Consejo de Estado consiste en la preparación y elaboración de un texto, que puede ser incluso articulado, a partir de los objetivos, criterios y límites que aquél le señale el Gobierno, gozando, pues, de un gran margen de discrecionalidad. Esta reforma legislativa choca con la caracterización del Consejo de Estado como órgano de relevancia constitucional (por tanto sin capacidad de dirección política alguna) y como órgano auxiliar o técnico (y por ello, no político), que desarrolla una función netamente consultiva. Me he pronunciado muy críticamente respecto de esta reforma legal en Vera Santos, J. M. «De la elaboración de propuestas de reforma constitucional por el Consejo de Estado», en Vera Santos, J. M. y Díaz Revorio, F. J. (coords.) La reforma estatutaria y constitucional. Madrid: La Ley, 2009, págs. 737-771.

20 Arts. 146 RCD y 152 RS. En los artículos 126 y 108 respectivamente, regulan ambas Cámaras los requisitos para proceder a la iniciativa legislativa ordinaria: un grupo parlamentario o quince diputados en el Congreso, frente a un grupo parlamentario o veinticinco senadores en la Cámara Alta. Existen algunas especificidades procedimentales más (por ejemplo, si se presenta la iniciativa por el Senado...), pero nos remitimos a los manuales al uso, por no suponer una diferencia esencial respecto al procedimiento legislativo ordinario. DE VEGA GARcía (o. c., pág. 133), destaca cómo realmente no son las Cámaras las que gozan de iniciativa para la reforma: son esa quinta parte de los diputados o dos grupos parlamentarios y cincuenta senadores que no pertenezcan al mismo grupo quiénes la atesoran. Así, indica el catedrático complutense recientemente fallecido, bien que con un error aritmético: «por paradójico que pueda resultar, la iniciativa, en cuanto propuesta para que se declare abierto el procedimiento de reforma, no corresponde en puridad -a pesar de lo estatuido en el artículo 87 de la Constitución- ni al Congreso ni al Senado. Son setenta y cinco diputados (artículo 146 del Reglamento del Congreso) ó 50 senadores (artículo 152 del Reglamento del Senado) quienes, al estar habilitados para suscribir proposiciones de reforma constitucional, ejercitan realmente el derecho de iniciativa. Lo que las Cámaras hacen, en cuanto órganos colegiados que expresan una voluntad unitaria, es decidir sobre las iniciativas ajenas (del Gobierno, o de las Asambleas legislativas de las Comunidades Autónomas), y sobre las propuestas surgidas de los partidos». 
viene regulada en cada uno de los Estatutos de Autonomía y Reglamentos parlamentarios correspondientes de su Asamblea respectiva. Si la iniciativa de reforma se presentase ante la Mesa del Congreso, dicho órgano será el encargado de examinarla y, una vez verificado el cumplimiento de los requisitos formales, se tramitará como cualquier otra proposición de ley, bien que su defensa se encargará a una delegación de la Asamblea autonómica proponente, tal y como el propio artículo $87 \mathrm{CE}$ establece ${ }^{21}$. Si las Asambleas regionales optan por pedir al Gobierno que adopte un proyecto de ley de reforma, éste puede, o bien atender la demanda, en cuyo caso se tramitaría como cualquier otra iniciativa de reforma auspiciada por el Ejecutivo, o bien negarse a adoptar el mismo, y dicha iniciativa autonómica habría concluido ${ }^{22}$.

Incluyo, siguiendo a la mejor doctrina ${ }^{23}$, el estudio de las previsiones recogidas en el artículo 169 de nuestra Constitución como límites a la iniciativa de reforma y no como limitaciones a la reforma en general. Reza el artículo citado: «No podrá iniciarse la reforma constitucional en tiempo de guerra o de vigencia de algunos de los estados previstos en el artículo $116{ }^{24}$.

${ }^{21}$ El artículo 126.1 RCD así lo reconoce igualmente.

22 Algunos autores defienden que en este último caso, la solicitud al Gobierno por parte de la Asamblea legislativa autonómica, no estamos ni siquiera ante una iniciativa legislativa indirecta sino que simplemente no existe como tal iniciativa (así, Álvarez Conde, E. y Tur Ausina, R. Derecho constitucional. Madrid: Tecnos, 2015, pág. 655). Como posteriormente destacaré (vid. nota 74 ), defiendo la subsidiariedad de la iniciativa para la reforma constitucional de las asambleas regionales, así como también la exclusión absoluta de las Comunidades Autónomas en todo el posterior proceso de reforma. En suma, es una muestra más de que España no es un Estado federal. Confundir los intereses generales de España con los propios de territorios descentralizados políticamente en aras a un siempre mencionado, y no siempre cumplido, principio de cooperación interinstitucional, nunca puede ocultar otro principio, el de supra y subordinación que refería García Pelayo, en beneficio del Estado, así como la diferencia entre soberanía y autonomía. La experiencia demuestra que, en las relaciones territoriales, dichos términos se han confundido en demasiadas ocasiones en España, tema éste que, claramente, merece ser estudiado y objeto de reforma que estabilice dichas relaciones de una manera definitiva.

${ }^{23}$ Por todos, Pérez Royo (La reforma..., o. c., pág. 150). Y es que, « (...) en realidad el artículo 169 CE se encuentra mal ubicado» porque «no es más que un apéndice del artículo 166, del cual hubiera debido constituir el apartado 2» (Contreras, M. «Sobre el Título X de la Constitución española: De la reforma constitucional», Revista de Derecho Constitucional, n. ${ }^{\circ} 37,1992$, pág. 313).

24 Artículo 116 CE: «1. Una ley orgánica regulará los estados de alarma, de excepción y de sitio, y las competencias y limitaciones correspondientes. 2. El estado de alarma será declarado por el Gobierno mediante decreto acordado en Consejo de Ministros por un plazo máximo de quince días, dando cuenta al Congreso de los Diputados, reunido inmediatamente al efecto y sin cuya autorización no podrá ser prorrogado dicho plazo. El decreto determinará el ámbito territorial a que se extienden los efectos de la declaración. 3. El estado de excepción será declarado por el Gobierno mediante decreto acordado en Consejo de Ministros, previa autorización del Congreso de los Diputados. La autorización y proclamación del estado de excepción deberá 
Estas limitaciones temporales en tan bautismal momento del proceso de reforma, resultan adecuadas en situaciones especialmente complejas, ya que parece necesario que cualquier reforma constitucional se lleve a cabo en un estado de calma política. Siendo cierto lo anterior, también me parecen insuficientes respecto al resto de la tramitación de la reforma, al considerar que deberían extenderse a cualquier trámite de la misma, siguiendo, por cierto, los ejemplos extranjeros ${ }^{25}$ y como se argumentó, evidentemente con poco éxito, en la tramitación constituyente ${ }^{26}$. En suma, creo más adecuada una regulación que prohibiese también el desarrollo del procedimiento de reforma una vez iniciado, si se declarase alguno de los estados de emergencia.

Las prevenciones que pretende garantizar el artículo 169 CE pueden resultar excesivas e inútiles ${ }^{27}$. Excesivas al referirse al estado de alarma, referido a la declaración gubernamental en todo o parte del territorio en caso de catástrofes naturales, accidentes de gran magnitud, epidemias o paralización de servicios públicos esenciales $^{28}$. E inútiles si nos hallamos ante el resto de las situaciones de excepción referidas en el artículo, ya que lo fáctico se impone a lo normativo o, en el caso de la autorización/declaración, respectivamente de los estados de

determinar expresamente los efectos del mismo, el ámbito territorial a que se extiende y su duración, que no podrá exceder de treinta días, prorrogables por otro plazo igual, con los mismos requisitos. 4. El estado de sitio será declarado por la mayoría absoluta del Congreso de los Diputados, a propuesta exclusiva del Gobierno. El Congreso determinará su ámbito territorial, duración y condiciones. 5. No podrá procederse a la disolución del Congreso mientras estén declarados algunos de los estados comprendidos en el presente artículo, quedando automáticamente convocadas las Cámaras si no estuvieren en período de sesiones. Su funcionamiento, así como el de los demás poderes constitucionales del Estado, no podrán interrumpirse durante la vigencia de estos estados. Disuelto el Congreso o expirado su mandato, si se produjere alguna de las situaciones que dan lugar a cualquiera de dichos estados, las competencias del Congreso serán asumidas por su Diputación Permanente. 6. La declaración de los estados de alarma, de excepción y de sitio no modificarán el principio de responsabilidad del Gobierno y de sus agentes reconocidos en la Constitución y en las leyes». Este precepto fue desarrollado mediante la Ley orgánica 4/1981, de los estados de alarma, excepción y sitio.

${ }^{25}$ Vid. arts. 89 de la Constitución francesa o 198 de la belga, en la que esta limitación se refiere a «iniciar y proseguir» o «iniciar y tramitar» el procedimiento de reforma constitucional. Proseguir, tramitar... términos éstos que nos llevarían a aludir no a límites de la iniciativa, como es el caso, sino a limitaciones de la totalidad del procedimiento de reforma.

${ }^{26}$ Se cambió la redacción de este artículo en la Comisión de Asuntos Constitucionales y Libertades Públicas, de 20 de junio antes citada en nota 17. Fue una enmienda del Diputado Solé Tura la que restringió la redacción del texto de la Ponencia, que abogaba por ampliar este límite no sólo a la iniciativa sino a la consiguiente tramitación. Fraga Iribarne se opuso, bien que sin éxito.

27 Así las califica DE Vega García, P. «Reforma constitucional», en Diccionario del sistema político español». Madrid, Akal, 1984, págs. 805-806. También en La reforma constitucional... o. c., págs. 160-162.

${ }^{28}$ Vid. art. 4 de la Ley orgánica 4/1981, de 1 de junio. 
excepción y sitio, al corresponder al Congreso de los Diputados a solicitud del Gobierno, o a la propia Cámara baja, parece poco probable, aunque no resulte imposible, que esta Cámara proceda a realizar la autorización o la declaración y, en paralelo, inicie la reforma ${ }^{29}$. Respecto a dicha «inutilidad» planteo alguna reserva, ya que no podemos olvidar el carácter plural de los sujetos legitimados para iniciar la reforma constitucional, lo que hace parcial dicha argumentación, centrada únicamente en la posible y lógica actuación del Congreso de los Dipu$\operatorname{tados}^{30}$.

\subsection{El procedimiento de reforma recogido en el artículo 167}

Recordemos, en primer lugar las prescripciones del meritado precepto: «1. Los proyectos de reforma constitucional deberán ser aprobados por una mayoría de tres quintos de cada una de las Cámaras. Si no bubiera acuerdo entre ambas, se intentará obtenerlo mediante la creación de una Comisión de composición paritaria de Diputados y Senadores, que presentará un texto que será votado por el Congreso y el Senado.

2. De no lograrse la aprobación mediante el procedimiento del apartado anterior, y siempre que el texto bubiere obtenido el voto favorable de la mayoría absoluta del Senado, el Congreso, por mayoría de dos tercios, podrá aprobar la reforma.

3. Aprobada la reforma por las Cortes Generales, será sometida a referéndum para su ratificación cuando así lo soliciten, dentro de los quince días siguientes a su aprobación, una décima parte de los miembros de cualquiera de las Cámaras.»

Varias consideraciones deben realizarse al respecto, con la finalidad de clarificar diversas cuestiones, siguiendo las previsiones reglamentarias y doctrinales. En primer lugar, ha de destacarse que, tanto el Reglamento del Congreso de los

${ }^{29}$ El artículo 13 de la norma citada alude al estado de excepción indicando que se requiere la autorización del Congreso de los Diputados al Gobierno para que éste lo declare si resultasen gravemente alterados el libre ejercicio de los derechos y libertades ciudadanas, el normal funcionamiento de las instituciones democráticas o de los servicios esenciales de la comunidad, o una grave alteración del orden público no solucionable por las vías ordinarias. Por su parte, el artículo 32 indica que «cuando se produzca o amenace producirse una insurrección o acto de fuerza contra la soberanía o independencia de España, su integridad territorial o el ordenamiento constitucional, que no pueda resolverse por otros medios, el Gobierno (...) podrá proponer al Congreso de los Diputados la declaración del estado de sitio».

La referencia constitucional al «tiempo de guerra», concepto jurídico bastante indeterminado, diría yo, introduce aún más indefinición.

${ }^{30}$ Más allá de posibles iniciativas provenientes de los otros órganos constitucionalmente competentes, $\mathrm{y}$ «contraprogramando» al propio homenajeado con su argumentación antes referida (vid. notas 15 y 20), no es en puridad el Congreso de los Diputados y el Senado los que gozan de dicha iniciativa, sino una fracción, por cierto no demasiado elevada, de sus componentes. 
Diputados como el del Senado indican que la votación y correspondiente mayoría cualificada de tres quintos de cada una de las Cámaras, a las que se refiere el apartado primero debe realizarse respecto a la totalidad del texto de reforma presentado $^{31}$. De igual manera he de advertir que la posibilidad de que se reúna una Comisión «de conciliación», encarnada en la Comisión Paritaria Mixta Congreso-Senado, destaca como novedad dentro de la normativa comparada y ejemplifica esa tendencia a dotar al procedimiento de «alternativas» variadas para la consecución de la reforma iniciada: si no se aprueba la misma por las tres quintas partes de los miembros de ambas Cámaras, se posibilita la creación de esta Comisión Mixta paritaria para conciliar, para acordar un nuevo texto. La propia regulación constitucional parece perseguir que la reforma se produzca, excepto que, primero, no se alcance la citada mayoría cualificada y, después, no se logre la aprobación del nuevo texto ${ }^{32}$ que proponga la Comisión paritaria, en un primer momento, por idéntica mayoría de tres quintos o, posteriormente por mayoría absoluta del Senado y dos tercios de los diputados, como indica el apartado segundo del artículo $167 \mathrm{CE}^{33}$.

En cuanto al referéndum al que se refiere el apartado tercero, se nos presenta como una cláusula de defensa de las minorías, y no sólo parlamentarias ${ }^{34}$. Me explico: en realidad, para que no se proceda a la convocatoria del mismo, el proyecto de reforma ha de lograr un respaldo de, al menos, el noventa por ciento de los diputados y de los senadores. Reitero: el noventa por ciento de aprobación en ambas Cámaras ${ }^{35}$, nueve diputados y senadores de cada diez miembros de su

31 Vid. arts. 146.2 RCD y 156.1 RS. Parece evidente la razón: la aprobación por artículos o títulos podría conllevar la desnaturalización, en un sentido u otro, de la iniciativa de reforma.

32 De los artículos reglamentarios citados ut supra, se deduce esta posibilidad de presentar un texto novedoso para su aprobación por ambas Cámaras.

${ }^{33}$ La doctrina alude a la redacción del apartado segundo como momento en el que la preeminencia del Congreso de los Diputados se abre paso, prioridad que puede o no ser compartida pero que, es evidente, se produce.

${ }^{34}$ De Vega García, La reforma constitucional, o. c., pág. 145, considera este referéndum facultativo, como un elemento básico para garantizar los derechos de las minorías «frente a posibles e hipotéticos abusos de las mayorías parlamentarias, que encontrarán en l'appel au peuple el freno más efectivo a cualquier veleidad de convertirse en poder constituyente y soberano». Alude a la opinión del maestro complutense, respecto a la protección de las minorías como elemento básico de cualquier procedimiento de reforma constitucional, ARANDA ÁlvareZ, E. «La «sustancialidad» del procedimiento para la reforma constitucional», en Teoría y Realidad Constitucional, n. ${ }^{\circ}$ 29, 2012, págs. 389-408 (394).

35 Aparte de los denominados senadores autonómicos (art. 69.5 CE), es cierto que el sistema mayoritario que propone para las elecciones a senador el artículo 166 de la LOREG, dentro de la circunscripción provincial, conlleva que en el seno de la Cámara Alta gocen de preeminencia los grupos parlamentarios que representan a la mayoría de gobierno y de la oposición. La lógica indi- 
Cámara respectiva deben apoyar la reforma emprendida. En el caso contrario, la lógica indica que se tenga que celebrar el referéndum, ya que así se solicitaría ${ }^{36}$. Se convierte así el referéndum en una cláusula de cierre muy relevante, ya que su convocatoria potestativa queda preterida al exigirse a partir de una muy escasa presencia política. Y es que, si ni siquiera uno de cada diez diputados o senadores muestran su disconformidad, se puede decir que existe un consenso muy extendido, bien que mostrado «en negativo», lo que hace que las minorías queden plausiblemente defendidas ${ }^{37}$.

Así pues, el procedimiento recogido en este artículo basa su rigidez en la mayoría cualificada ${ }^{38}$, y aparece definido por la doctrina como procedimiento simple, ordinario y yo le adjunto otro matiz, como procedimiento «de alternativas», todo ello teniendo en cuenta que dicha taxonomía aparece de modo inverso en su aplicación al regulado en el artículo siguiente, calificado como «agravado» o «extraordinario» (sic), y al que yo añado también que es un pro-

ca que para proceder a una reforma constitucional al menos los dos partidos mayoritarios (de gobierno y oposición, incluso de gobierno si se diera el caso), deberían estar de acuerdo. De otra manera ese porcentaje del diez por ciento de votos contrarios a la reforma sería ampliamente superado (también en el Congreso).

36 Destaca E. García en la «Encuesta» antes citada (pág. 30) que» (...) en este sentido permítaseme señalar el singular papel que juega el pueblo en la reforma (...) [dice que en el caso del 168 se pronuncia siempre y, respecto al $167 \ldots$... Semejante recurso sólo se explica como un intento de disuadir de proceder a cualquier reforma que no esté ampliamente consensuada al menos por un 90\% de las cámaras, lo que en términos de representación política supone todavía la exigencia de un mayor respaldo». Critica esta realidad, entre otros, López Aguilar, J. F. «De la Constitución «irreformable» a la reforma constitucional «exprés»», en Teoría y Realidad Constitucional, n. ${ }^{\circ}$ 29, 2012, págs. 199-218 (215) «Pues bien, ciñéndonos al procedimiento ordinario, en realidad si nos fijamos, sólo si una mayoría de más de 9/10 de ambas Cámaras están a favor de la reforma constitucional, ésta podrá obviar el referéndum, pues es altamente probable desde el punto de vista político que si más de 1/10 vota en contra y pierde la votación, lo siguiente que hará será solicitar un referéndum». Alaba la importancia de acudir al referéndum, desde posturas que no comparto Salazar Benítez, O. «La Constitución domesticada: algunas reflexiones críticas sobre la reforma del artículo 135 CE», en Teoría y Realidad Constitucional, n. ${ }^{\circ}$ 29, 2012, págs. 409-432 (425-426). Por supuesto, esta protección de las minorías no conlleva que, si existe un consenso, imaginemos, del 70, 75 u 80 por ciento, el resultado del mismo vaya a ir en consonancia con el mismo, superando sin mayores dificultades dicha consulta.

37 Como más adelante destaco, no soy partidario de la utilización de los referéndums establecidos en los artículos 167 y 168 CE si se previesen cláusulas de intangibilidad. Dicho lo cual, y atendiendo a la regulación actual, tanto el uno como el otro tienen su justificación. De ahí que defienda, en la primera parte de este trabajo, su presencia en ambos procedimientos con los argumentos correspondientes.

${ }^{38} \mathrm{Vid}$. nota 12 sobre las referencias sobre procedimientos de reforma en Derecho comparado similares al previsto en este artículo. 
cedimiento necesariamente «consecutivo» ${ }^{39}$. El artículo $167 \mathrm{CE}$ posibilita la consecución de la reforma emprendida. Y si apareciese alguna dificultad en las mayorías requeridas, incluso se abre un proceso de conciliación intercameral y un cambio en las mayorías exigidas a cada Cámara para poder concluir la reforma. Todo ello bajo la tutela y respeto a las minorías que supone un referéndum que, si bien no es obligatorio, se nos parece como de muy sencilla utilización en cuanto el número de parlamentarios que lo puede solicitar ${ }^{40}$.

Numerosos autores abogan por que el previsto en el artículo 167 sea el único procedimiento para proceder a la reforma constitucional. Y yo no estoy de acuerdo en que el sencillo procedimiento parlamentario del artículo $167 \mathrm{CE}$ fuese el más adecuado para regular la reforma parcial de cualquier materia recogida en la Constitución. Creo que la mayoría solicitada de tres quintas partes, sin ni siquiera acudir a la aprobación de una doble Legislatura o sin la obligación de una consulta a los ciudadanos, significaría una absoluta desvalorización de nuestra Constitución. Como antes he destacado, se confundiría la democracia «de la Constitución» y la democracia «en la Constitución» ${ }^{41}$, pasando así del consenso para convivir en paz y libertad al puntual acuerdo torticero.

\subsection{El procedimiento de reforma del artículo 168}

Parto de un dato indiscutible, contrario a lo predicado respecto al precepto anterior: el artículo 168 de nuestra Constitución, la regulación que contiene, es objeto mayoritario de severas críticas. Si bien es cierto que presenta graves inconvenientes en lo tocante a la atribución material y al reconocimiento - por cierto, indefinido - de la posibilidad de una reforma total de la propia Constitución, creo que hay que destacar al menos dos cuestiones.

En primer término, desde el punto de vista relacional, desde el prisma de una interpretación sistemática, dicha regulación ha de ponerse en relación con el antes citado procedimiento del artículo 167 de nuestra Constitución; en segundo término, también desde la óptica de una interpretación sistemática, ha de destacarse que en la normativa constitucional española no existen, como decía, cláusulas de intangibilidad ${ }^{42}$. En ambas cuestiones, casi siempre

39 Respecto a la cuestión terminológica y mi crítica a la misma vid. nota 66 y textos concordantes, así como el apartado 2.1.

40 Vid. notas 34 a 37.

${ }^{41}$ Vid. nota 8.

${ }^{42}$ Discrepo con los autores que predican que el artículo 168 CE conforme una «semiintangibilidad encubierta», como después argumento (vid. notas 50 a 58 y apartado 3.2). Califica a las 
olvidadas o preteridas, es donde radica la coherencia de nuestro «doble procedimiento», su sistematicidad.

Leemos en el artículo 168: «1. Cuando se propusiere la revisión total de la Constitución o una parcial que afecte al Título preliminar, al Capítulo segundo, Sección primera del Título I, o al Título II, se procederá a la aprobación del principio por mayoría de dos tercios de cada Cámara, y a la disolución inmediata de las Cortes.

2. Las Cámaras elegidas deberán ratificar la decisión y proceder al estudio del nuevo texto constitucional, que deberá ser aprobado por mayoría de dos tercios de ambas Cámaras.

3. Aprobada la reforma por las Cortes Generales, será sometida a referéndum para su ratificación.»

Comienzo aludiendo a las cuestiones referidas a las atribuciones materiales. Esta regulación diferencia entre la reforma total (que denomina revisión) ${ }^{43}$ y la parcial que afecte a determinados Títulos o Secciones. Considero que la recepción en nuestro ordenamiento de la mera posibilidad de proceder a una reforma total de la Constitución presenta numerosos problemas doctrinales, además de que supone una absoluta deslealtad axiológica democrática, confundiendo el poder constituyente con el de reforma constitucional ${ }^{44}$. Lo anterior se agrava, si cabe, al no establecer la normativa, ni cualitativa ni cuantitativamente, cuando nos

cláusulas de eternidad como «figuras de notable interés y utilidad, sobre todo en países socialmente propensos a la revisión periódica de sus bases estructurales» Belda PÉrez-PEdrero, E. «Los límites a la reforma constitucional ante propuestas más propias de una revolución», en Teoría y Realidad Constitucional, n. ${ }^{\circ} 29,2012$, págs. 261-288 (267). Estoy de acuerdo.

43 Por su claridad expositiva, respecto a la definición terminológica concreta de lo que doctrinalmente se conoce como reforma, revisión, supresión, destrucción, mutación o quebrantamiento constitucional vid. SÁNCHEZ GonZÁLEZ, S. «Reforma mutación y... quiebra constitucionales», en Teoría y Realidad Constitucional, n. ${ }^{\circ}$ 19, 2007, págs. 295-310 (297-298).

44 Torres del Moral, A. Principios de Derecho constitucional español. Madrid: Facultad de Derecho de la Universidad Complutense de Madrid, 1992, vol. 1, pág. 195. Sigo así, entre otros, a De Vega García, La reforma constitucional... o. c., pág. 239. García-Atance, o. c., págs. 82 y 84 destaca: «La reforma total, por la vía de la revisión, se traduciría en el resultado de legalizar la revolución», pues «no hace sino producir el efecto de una revolución respecto del orden instituido previamente». Añade Balaguer Callejón, F. «El status constitucional de la reforma y la fragmentación del poder constituyente», en VV. AA. La democracia constitucional. Estudios en homenaje al profesor Francisco Rubio Llorente, Madrid: Congreso de los Diputados / Tribunal Constitucional/ Universidad Complutense de Madrid/Fundación Ortega y Gasset/Centro de Estudios Políticos y Constitucionales, 2002, pág. 117, que cuando esto ocurre la frontera que separa el poder constituyente originario y el derivado se torna ciertamente inestable. Por eso García-Atance (o. c., págs. 273 y ss.), rechaza, de todo punto, la posibilidad de la reforma total, pues vendría a constituir que un orden constituido de revisión pudiese modificar por vía procedimental la decisión político fundamental, competencia, naturalmente, del poder constituyente. 
encontramos ante una revisión total. Soy partidario de definir la misma atendiendo no sólo a criterios de cantidad, sino también y sobre todo, cualitativos ${ }^{45}$, bien que ante la evidente indefinición de los mismos, debería ser el Tribunal Constitucional quien pudiera pronunciarse ${ }^{46}$.

Los artículos 1 a 9, 15 a 29 y 56 a 65 recogen las materias objeto de protección por este artículo. Sobran materias, bien que creo que no tantas como algunos reseñan; de otro lado, faltan en este elenco elementos vertebradores de nuestra realidad constitucional. El mayor grado de rigidez que alcanza a las materias protegidas por el artículo $168 \mathrm{CE}$, trataría de garantizar al máximo la definición territorial del Estado, apuntalando los principios de unidad y autonomía, así como la Jefatura de Estado monárquica, sin olvidar la finalidad última de cualquier estructuración estatal: los derechos fundamentales y libertades públicas, que conforman el tercer bloque material con mayor protección.

No olvido la inclusión en este artículo de materias que pueden considerarse también muy relevantes políticamente, sobre todo después de superado un régimen autoritario de cuarenta años; me estoy refiriendo al diseño de las funciones constitucionales de partidos políticos, sindicatos o Fuerzas Armadas (arts. 6, 7 y $8 \mathrm{CE}$ ) o los principios que recoge el artículo $9^{47}$. Incluyo también entre los preceptos especialmente relevantes, tanto por su sentido simbólico como de integración, la definición y protección de la bandera y lengua oficial (arts. 3 y 4 CE).

Sí comparto la crítica doctrinal que atiende a la no inclusión en la protección agravada que propone el precepto estudiado, de artículos como el 14, verdadero frontispicio de la posterior enumeración de derechos y libertades básicas, o el 53, referido a las garantías de dichos derechos fundamentales ${ }^{48}$, bien que considero

45 Creo con Pérez Royo (La reforma..., o. c., págs. 196-197) que para determinar si una revisión es o no total «habrá que tomar en consideración tanto elementos cuantitativos del tipo de los que se apuntaron en el proceso constituyente: número de artículos o un Título completo de la Constitución, etc., como cualitativos: que la reforma afecte a alguna institución que pudiera ser definida como órgano inmediatamente constitucional y singularmente relevante en el sentido de que no solo está definida y regulada en sus aspectos esenciales en la propia Constitución, sino que además su presencia en el edificio constitucional es decisiva. Por ejemplo, el Tribunal Constitucional como institución no figura entre los contenidos especialmente protegidos por el artículo 168 y, sin embargo, una reforma que suprimiera el control de constitucionalidad de la ley sería, en mi opinión, una revisión, una reforma total, en la medida en que cambiaría una pieza clave del edificio constitucional».

46 Vid. nota 49. Utilizo igualmente al Tribunal Constitucional como garante material de la reforma propuesta en el modelo referido en el apartado 3.2. A).

${ }^{47}$ Me refiero, por ejemplo, a los principios de constitucionalidad y de legalidad, de interdicción de la arbitrariedad de los poderes públicos o de publicidad de las leyes.

48 Además, en virtud de dicha rigidez, parece claro que la inclusión de nuevos derechos fundamentales debería hacerse según lo indicado en este artículo. 
que los mismos, a partir de un interpretación sistemática, deberían considerarse igualmente protegidos por este artículo ${ }^{49}$, bien que esta postura conlleva una indefinición que posibilitaría dos situaciones dicotómicas: dotar de la mayor rigidez a gran parte de los preceptos constitucionales o quedar, al contrario, en poco más que en una mera disquisición teórica.

$Y$ hacemos otra parada en el camino, por aquello de vislumbrar nuevos molinos, quién sabe si reales o imaginarios: lo anterior incide, a contrario sensu, en que nuestra Constitución no recoge cláusula de intangibilidad alguna ${ }^{50}$. Defender lo

En el fondo, estas últimas consideraciones parten de considerar erróneamente el artículo 168 CE como cláusula de intangibilidad encubierta. Es a partir de dicha cuestión que se compara la muy concisa regulación de las mismas en otros textos constitucionales con la extensión material de nuestro artículo meritado.

${ }^{49}$ Vid., por su claridad, la explicación de Bilbao, Rey y Vidal (o. c., pág. 292) «(...) la división de materias no es puramente topográfica o numérica. Así cualquier modificación que afecte sustancialmente a algunas de las materias del 168, aunque no sea un precepto incluido dentro de los títulos o secciones mencionados en dicho artículo, deberá realizarse por esa vía para preservar el núcleo definitorio de la forma de Estado. Lo que se protegen son los principios estructurales, no preceptos concretos» (continúan loa autores aludiendo a ejemplos como la supresión del artículo 53 o del Tribunal Constitucional). De nuevo debería ser, pues, el Tribunal Constitucional quien valorara esta opción como vuelvo a reflejar en nota 76 y he referido antes en nota 46.

50 «Para unos, dichas cláusulas tienen un valor riguroso y total, y para otros, solo constituyen retórica constitucional» (SÁNCHEZ FerRIZ, R. Introducción al Estado constitucional, Ariel, Barcelona, 1993, pág. 272). Otros las califican como garantes de los pilares en que se asienta la legitimidad constitucional, es decir, los fundamentos del orden ideológico y valorativo en que reposa el régimen constitucional (DE Esteban, J. y González-Trevijano, o. c., pág. 719). De la misma opinión, por ejemplo, Farias García, P. «Consideraciones sobre la reforma constitucional», Revista General de Legislación y Jurisprudencia, t. LxxviII, n. . 246, 1979, pág. 253 y 255: «las normas declaradas intangibles componen una superlegalidad que, al margen del hecho revolucionario, marcan el límite del poder constituyente, sirven para orientar a los Tribunales, y cumplen una función de pedagogía política»). También Pizzorusso, quien concluye que la aceptación de estas cláusulas pétreas parte de la constatación de la existencia de principios supremos de la Constitución material con eficacia superior a la de las normas producidas por fuentes de rango constitucional (Pizzorusso, A., Lecciones de Derecho Constitucional. Madrid: Centro de Estudios Constitucionales, 1984, pág. 84. En términos generales, siguiendo a DE VEGA GARCía «lo que se hace con ellas es constitucionalizar el orden de valores que inspiran ideológicamente el régimen político, creando un centro referencial pare el juez» (La reforma constitucional», en VV. AA., Estudios sobre el proyecto de Constitución. Madrid: Centro de Estudios Constitucionales, 1978, págs. 229 y 230). Por no hablar del freno que supondría para las fuerzas parlamentarias que contasen con las mayorías necesarias para reformar la Constitución (PÉREZ RoYo, J., La reforma ... o. c., pág. 210). Siguiendo esta postura, revalorizando las cláusulas de intangibilidad como elementos vertebradores de una posible introducción en España del concepto de democracia militante, aplicada a la exclusión de partidos antisistema, vinculados al terrorismo etarra, vid. Fernández DE CASADEVANTE MaYorDOMO, P. «La prohibición de formaciones políticas como mecanismo de defensa del Estado y el debilitamiento de dicha protección tras las polémicas decisiones sobre Bildu y Sortu», en Revista 
contrario sería tanto como negar que nuestra regulación permite la reforma total, o que no existe un procedimiento previsto para cambiar la forma de Estado, los derechos fundamentales o la articulación autonómica de España a través de los principios de unidad, autonomía y solidaridad, por poner algunos ejemplos de materias que en otros países se protegen mucho más que en el nuestro, conformando cuestiones intocables vía reforma constitucional. Vamos que defiendo que en España no existe clausulado de intangibilidad «ni cubierto ni encubierto».

Del examen de los contenidos que recoge el constitucionalismo comparado ${ }^{51}$, estos límites materiales explícitos afectan a diversas materias, todas ellas relevantes, esenciales, para la correcta comprensión jurídico-política de cada sistema democrático. En primer lugar aludimos a aquellas limitaciones que prohíben la modificación de la forma de Estado ${ }^{52}$. También encontramos cláusulas de intangibilidad referidas a la forma democrática de gobierno ${ }^{53}$. En tercer lugar observamos que las declaraciones de derechos también son objeto de intangibilidad ${ }^{54}$, así como la modificación de la estructura federal ${ }^{55}$. De igual manera la doctrina añade otros supuestos tales como la prohibición de reforma de aquellos principios

Europea de Derechos Fundamentales, n. ${ }^{\circ}$ 26, 2016, págs. 111-137 (115-117). Otra parte de la doctrina consideran que las cláusulas de intangibilidad resultan disquisiciones políticas alejadas de la realidad (Loewenstein, K. Teoría de la Constitución. Barcelona: Ariel, 1986, pág. 192: «En su desarrollo normal de la dinámica política puede ser que hasta cierto punto se mantengan firmes, pero en época de crisis son tan sólo pedazos de papel barridos por el viento de la realidad política»). Excelente el resumen doctrinal sobre la problemática de la intangibilidad el que presenta DE VEGA GARCÍA (La reforma constitucional..., o. c., págs. 247-267): desde su a veces posible vinculación con «circunstanciales motivaciones» que denotan «debilidades políticas e institucionales graves», no quita para que la intangibilidad suponga el asentimiento de los valores e ideologías sobre los que descansa el régimen político (págs. 247-248). También califica estas cláusulas como elemento diferenciador entre el poder constituyente y el poder de reforma, algo que desde luego echo de menos en la redacción de nuestro artículo 168 CE (págs. 255-256).

51 Respecto a cláusulas de intangibilidad en derecho comparado vid. Vera SAntos La reforma, o. c., págs, 259-266.

52 Por ejemplo, las Constituciones francesas de la III República (artículo 8 de la Ley constitucional de 25 de febrero de 1875), de 1946 (artículo 95) y de 1958 (artículo 89); también la Constitución italiana de 1947 (artículo 139), pues impide la modificación de la forma republicana de gobierno, o la Constitución griega de 1952 (artículo 108) sobre la revisión de la forma de gobierno monárquica.

53 Artículo 150 de la Constitución del Land de Hesse o el artículo 756 de la propia del Land de Baviera, «constituciones» que lo son en ambos casos de Estados ya federados.

54 Artículo 290 de la Constitución de Portugal o el 79.3 de la Constitución alemana.

55 Tal es el caso del artículo V de la Constitución americana de 1787, según el cual ningún Estado puede ser privado sin su consentimiento de su igual representación en el Senado. 
definitorios de la Constitución ${ }^{56}$, o, por último, se refieren a la intangibilidad expresa de las propias disposiciones sobre la reforma constitucional ${ }^{57}$.

En ningún caso nuestra regulación constitucional del procedimiento de reforma incluye al propio artículo $168 \mathrm{CE}$ como «autoprotegido», lo que ha permitido a algunos autores abogar por su reforma vía artículo 167 CE, «sacando» del mismo algunos o todos los preceptos, bien que la inmensa mayoría doctrinal se muestra en contra, aludiendo a un posible fraude contra la Constitución, por analogía al fraude de ley, destacando que todo procedimiento que afecte a la reforma constitucional tal y como está configurada, debe realizarse vía artículo $168^{58}$.

Toda vez que he reflexionado respecto al ámbito material sobre el que se proyecta la protección agravada del artículo estudiado, conviene a continuación hacerlo respecto al contenido procedimental del mismo. Como he destacado, el apartado primero de este artículo indica que si la reforma es total o afecta a los artículos señalados antes, tanto el Congreso de los Diputados como el Senado deberán aprobar «el principio» de reforma por una mayoría cualificada de dos

56 Son los casos de la Constitución de Noruega de 1814 (artículo 112) y, sobre todo, de la Ley Fundamental de Bonn de 1949, en cuyo artículo 79.3 señala expresamente que «es inadmisible toda modificación de la presente Ley Fundamental que afecte a la división de la federación en Länder, o al principio de cooperación de los Länder en la legislación o a los principios consignados en los artículos 1 y $20 »$.

57 Este fue el caso de la Constitución del Estado de Renania-Palatinado (artículo 129.3) en Alemania

58 Bilbao, Rey y Vidal (o. c., pág. 292) lo argumentan así: «En cuanto a la rigidez de las cláusulas de reforma del Título X (el problema de la «autorreforma» constitucional), el art. 168 no menciona estas normas, pero este silencio, esa laguna técnica, debe salvarse por vía interpretativa. Lógicamente, la reforma del Título X debe hacerse por el procedimiento del art. 168. De otro modo se desvirtuaría la garantía del 168 mediante una reforma previa por la vía del 167 que redujera su grado de rigidez. Lo dispuesto en el art. 168 carecería de efectividad si pudiera sortearse de esta manera.» Y continúan los autores citados yendo aún más allá: «Tampoco resulta admisible la reforma del 167 por la vía del propio 167 (para rebajar, por ejemplo, la mayoría exigida). Pero además de esta razón lógica o teórica, esta solución encuentra apoyo normativo: no hay nada que afecte mas al principio de soberanía popular del art. 1.2 CE que la alteración de las cláusulas de reforma». Como indicase ya DE OTTO (o. c., pág. 66) esto supondría un «patente fraude del sistema de reforma». Como era habitual en el autor, encontramos un excelente resumen sobre lo que significa esta reforma de doble grado en DE VEGA GARCía La reforma constitucional... o. c, págs. 265-267. Con absoluta claridad alude a que «la tesis de la reforma en doble grado resulta (...) tan ingeniosa como insostenible». El poder constituyente decidió, acertadamente o no, incrementar la protección de determinados aspectos y ningún poder constituido puede conculcar su manifestación constitucional superior. Quizás no hace falta que lo indique, por obvio, pero las posibles reformas a las que me refiero en el último apartado de este estudio, deberían realizarse, por tanto, a partir de los requisitos exigidos en el artículo $168 \mathrm{CE}$. 
tercios, procediéndose a continuación a la disolución inmediata de las Cortes. Dicha disolución, por cierto, no resulta ninguna novedad ni en el constitucionalismo español ni en el comparado ${ }^{59}$.

La aprobación de la decisión favorable a la iniciativa de reforma requiere una mayoría de dos terceras partes de diputados y senadores ${ }^{60}$, mediante un debate de totalidad en el que se discierne sobre la conveniencia y oportunidad de la reforma. No se discute por tanto el precepto o preceptos a reformar, ya que no se requiere un texto articulado, sino un documento que la Mesa del Congreso pueda calificar indicando el procedimiento constitucional (artículo 167 o 168) a seguir ${ }^{61}$.

59 Respecto a los precedentes patrios vid. arts. 379-383 de la Constitución de 1812, 111 de la de 1869 o el más cercano y evidente del artículo 125 de la Constitución de 1931, sin olvidarnos del artículo 116 del Proyecto federal de 1873. Respecto a ejemplos foráneos, destacan, entre otros, los casos belga, holandés o islandés, como reseño en la nota 12. La Constitución belga de 1994 se ha modificado en varias ocasiones. En Islandia, también se ha reformado su Norma fundamental, acogiendo también el sistema de doble Legislatura, en los años 1991, 1995 y 1999, dejando transcurrir, por tanto, el mandato parlamentario de cuatro años, entre cada reforma. Es cierto que los Textos constitucionales citados abogan por un procedimiento de doble legislatura pero no lo complementan/incrementan con la llamada a referéndum. En el caso belga, el artículo 195, para evitar la tendencia asambleario-constituyente de unas segundas Cámaras que pudieran hacer caso omiso de lo aprobado por las primeras, establece que aquellas «decidirán de común acuerdo con el Rey acerca de los temas sometidos a revisión». En el caso islandés no existe previsión similar. La clave, en consecuencia, no está en que proceda dicha disolución obligatoria y automática, sino en los apoyos con que cuenta la reforma y en la voluntad reformadora de los sujetos legitimados constitucionalmente, ex artículo $166 \mathrm{CE}$.

${ }^{60}$ Frente a quienes opinan que se trata de una mayoría excesiva, abogando por una mayoría simple, considero mejor que desde el comienzo del proceso de reforma exista un amplio acuerdo sobre la cuestión a revisar y el sentido de la misma. Lo contrario nos puede llevar a un rosario permanente de solicitudes y debates sobre temática muy compleja que serían utilizados políticamente de manera torticera, sabiendo de las pocas posibilidades de completar con éxito el cambio.

${ }^{61}$ El Informe del Consejo de Estado sobre la reforma constitucional ya citado, así lo reconoce en su página 250. En todo caso existen diversas opiniones al respecto que sintetiza muy eficazmente el órgano consultivo en su Informe de 2006. En resumen, partiendo del interrogante sobre lo que se entiende por «principio», una de las cuestiones «más debatidas por la doctrina en el análisis de este artículo de nuestra Constitución», disecciona la literalidad, indiscutiblemente caótica, de los artículos 147 del Reglamento del Congreso y 158 y 159 del propio de la Cámara Alta. Un estudio de la misma podría permitir creer que ese principio de reforma debe articularse como un "proyecto o proposición de ley» (art. 147.1 RCD), como un «texto constitucional» previo al «nuevo» al que alude el apartado 5 de este artículo, referido ya a la actividad de las segundas Cortes. También el artículo 159 del Reglamento del Senado, al referirse al momento de la ratificación del meritado principio, alude a «la reforma propuesta», dando a entender que puede, y debe, tratarse de un texto y no de un documento «de principios» (págs. 245 y 246).

Sin embargo, el propio Informe, establece previamente que «no es admisible hacer de aquellas o de estos [se refiere a leyes y/o Reglamentos parlamentarios, como es el caso] canon para la inter- 
Una vez alcanzada dicha mayoría en ambas Cámaras se produce la disolución de las Cortes. Indica la doctrina que esta disolución automática conlleva necesariamente que la campaña electoral de las elecciones legislativas subsiguientes gire en torno a la reforma en tramitación. Y así será necesariamente siempre que se afecte materialmente al «núcleo duro» de la Constitución, algo que, como se ha criticado, no ocurre siempre que se utiliza el procedimiento del artículo $168 \mathrm{CE}^{62}$.

De cualquier manera ha de advertirse que el pronunciamiento electoral respecto a la composición de la nueva Legislatura se va a producir respecto a un «principio» de reforma y posteriormente aprobarán el articulado concreto, cuestiones absolutamente diferentes en el tiempo, en contenidos, en teleología... ${ }^{63}$

Como escribía antes, una vez que son elegidas las nuevas Cámaras, éstas han de proceder, en primer lugar, a la ratificación del principio aprobado anteriormente. Es un clásico en la doctrina criticar el artículo 159 del Reglamento de la Cámara Alta, ya que solicita, ante el silencio de la propia Constitución, una ratificación del principio por mayoría absoluta, mientras que en el caso de la Cámara Baja basta con la obtención de la mayoría simple, siguiendo el ejemplo de los debates de totalidad ${ }^{64}$. Creo que se piden mayorías diferentes a las necesarias para lograr la aprobación definitiva del articulado que concretiza la reforma porque, en este primer momento, las nuevas Cámaras se pronuncian sobre el «principio» aprobado por las primeras. Es decir, deciden seguir la tramitación de la reforma. Sí es cierto que no parece adecuado que se exijan mayorías diferentes para dicha ratificación en cada Cámara.

pretación constitucional», y en sus argumentos siguientes destaca que la anterior postura doctrinal olvida que «si los Reglamentos parlamentarios hubieran querido disciplinar el modo de ejercer la iniciativa [se refiere a la posibilidad de presentar un texto articulado o, como poco, ciertamente desarrollado] lo habrían hecho, sin duda, de manera explícita, y no de manera indirecta o implícita»; en segundo término alude el Consejo de Estado, a que «no parece lógico que si el principio de la reforma ha de ofrecerse ya como texto articulado de ésta, no ofrezcan los Reglamentos vía alguna para que las Cámaras que han de aprobarlo introduzcan en ese texto los cambios que consideren oportunos, de manear que no les quede otra alternativa que la de aprobar o rechazar en su integridad el texto elaborado por el autor de la iniciativa (...) Por todo ello, cabe afirmar que la interpretación del artículo 168 debe prescindir, en principio, de los preceptos reglamentarios que lo desarrollan, para atender exclusivamente al propio texto constitucional» (págs. 246-247).

${ }^{62}$ Me refiero a la discusión sobre la presencia de determinadas materias dentro de la rigidez del precepto. Tampoco ha de olvidarse que si existe consenso generalizado sobre la cuestión objeto de reforma, tal enfrentamiento político quedaría desvaído.

${ }^{63}$ Si se pudiese cambiar radicalmente ese principio de reforma, se conculcaría tanto el espíritu como la letra del artículo $168 \mathrm{CE}$. Aparte de la lógica del argumento, vid. las explicaciones de Amérigo Alonso y Jeréz Calderón (o. c., págs. 198-199).

${ }^{64}$ Entre otros De Vega García (La reforma constitucional..., o. c., pág. 146), Pérez Royo (La reforma..., o. c., pág. 204) o De Esteban y GonzÁlez Trevijano (o. c., pág. 741). 
Establece la normativa citada que estas segundas Cámaras deciden por mayoría cualificada de dos terceras partes de sus miembros respecto a la articulación definitiva y concreta de la reforma. Frente a la opinión de algunos autores ${ }^{65}$, considero que, en ningún caso, y debido al carácter netamente acumulativo que presenta el artículo $168 \mathrm{CE}$, se podría proceder a la creación de una especie de Comisión Mixta, si no se alcanzase el acuerdo de dos terceras partes de los miembros de las dos Cámaras recién elegidas respecto del texto articulado que las mismas discuten. Estos colegas sostienen, así, que el procedimiento del artículo $168 \mathrm{CE}$ es una subespecie del general previsto en el artículo $167^{66}$.

Como «requisito ineludible para la perfección de la reforma constitucional ${ }^{67}$, podemos calificar la celebración del referéndum obligatorio al que se refiere el último apartado del artículo $168 \mathrm{CE}^{68}$. Y es que su carácter necesario conlleva también un endurecimiento de la rigidez de este procedimiento, abundando en la misma después del logro de mayorías cualificadas en ambas Cámaras, en diferentes momentos procesales, de la disolución de las primeras y la convocatoria de elecciones, amén del pronunciamiento de las nuevas sobre el texto concreto que luego se somete a aprobación popular a través de este referéndum.

Critica la doctrina ésta nueva llamada a la decisión electoral por reiterativa y por «encarecer» desmesuradamente un procedimiento ya de por sí muy complejo. Y yo estoy de acuerdo, pero... Lo vuelvo a explicar: como lo que aprueban las primeras Cámaras antes de su disolución no es en ningún caso el texto articulado sobre el que se pronuncia el pueblo en referéndum en este momento, creo que esta llamada a la voluntad popular encuentra su significado como última instancia verificadora de que las segundas Cámaras no trasgredan el contenido

${ }^{65}$ Discrepo así de quiénes abogan por la creación de una especie de comisión negociadora para alcanzar un texto consensuado ante la posibilidad de que el Senado presente enmiendas al texto del Congreso (art. 159 RS). Dicha comisión no se contempla en el texto constitucional ni tampoco los Reglamentos del Congreso de los Diputados o del Senado. Respecto a que el tan traído y llevado Reglamento de las Cortes Generales lo pudiera reconocer, creo que atentaría contra el espíritu restrictivo que emana del procedimiento que se acoge en el artículo $168 \mathrm{CE}$.

${ }^{66}$ Son realidades procedimentales diferentes que estableció el constituyente, guste o no. Procedimiento «de alternativas» en el caso del artículo 167 CE, y «consecutivo» del artículo 168 CE. El primero abre puertas ante el incumplimiento de alguno de los requisitos procesales solicitados: juega con mayorías variables en las Cámaras, con Comisiones Mixtas que permitan aprobar un texto de consenso; el segundo sólo plantea una posibilidad: o confluyen acuerdos, mayorías, y llamadas al electorado o no se produce la reforma. No lo digo yo: lo expresa claramente la Constitución de manera categórica

${ }^{67}$ Utilizo palabras tomadas de De Esteban y GonZÁlez Trevijano, o. c., pág. 741.

68 Respecto al procedimiento a seguir para la realización de la consulta vid. Ley orgánica 2/1980, reguladora de las distintas modalidades de referéndum. 
de la reforma que las primeras adoptaron como principio, evitando que éstas entren en una tendencia asamblearia que las haga confundir el poder constituyente con el limitado de reforma. El principio de reforma que se aprueba en la primera legislatura no es un texto definitivo sino «la intención» de su puesta en marcha. Las segundas Cámaras materializan dicha intención y, posiblemente, debido al juego de mayorías y minorías, puedan aprobar un texto que presente algún matiz diferente del que se discutiese en la previa campaña electoral realizada para la elección de las segundas Cámaras.

Insisto: el procedimiento estatuido en el artículo 168 de nuestra Constitución es complejo, mucho más con la necesaria llamada al pronunciamiento popular obligado a través de referéndum. Pero debo incidir en que, siguiendo situaciones similares comparadas ${ }^{69}$ y la propia realidad política española ${ }^{70}$, lo que nos encontramos como «prius» político es la absoluta falta de consenso entre los diferentes partidos para proceder a la realización de la reforma constitucional. Ante esto, la culpa recae sobre el procedimiento constitucionalmente estableci$\mathrm{do}^{71}$. En cualquier caso, puedo concluir que únicamente por la decisión de una mayoría electoral pírrica no se pueden reformar los aspectos básicos de nuestra convivencia. Ni siquiera para seguir en el poder, a Dios gracias.

\section{POSIBLES Y DESEABLES REFORMAS, O COMO EL SUEÑO DE LA RAZÓN PUEDE, AUNQUE NO DEBE, PRODUCIR MONSTRUOS}

Toda vez que he reflexionado respecto a la temática referida, el propio tenor del título de este estudio conlleva que vaya un paso más allá y me posicione respecto a propuestas concretas que mejoren, desde mi punto de vista, el procedimiento de reforma constitucional actual. Antes debo indicar de nuevo que el procedimiento de reforma estatuido en el Título $\mathrm{X}$ de nuestra Constitución es mejorable, técnica y materialmente, pero no es el culpable en absoluto de que nuestros políticos no hayan querido/podido reformar la Constitución. Es la falta

69 Vid. de nuevo nota 12.

70 No hace falta cita alguna para destacar que en España, hasta las elecciones de 20 de diciembre de 2015, para desarrollar la reforma constitucional, el mero acuerdo entre los dos partidos que se alternaban en el gobierno y como principal partido de la oposición, habría sido suficiente. Así lo refleja GARCía FERNÁNDEZ, J. «Reformas constitucionales posibles y reformas constitucionales imposibles. Notas previas a la reforma de la Constitución», en Teoría y Realidad Constitucional, 30, 2012, págs. 301-314 (307-308).

${ }^{71} \mathrm{Vid}$. nota siguiente respecto a la misma situación en el caso segundo republicano. Otra vez, observamos que nuestros representantes, si no obtienen el apoyo político suficiente para proceder a las reformas que proponen, desplazan la crítica a la regulación constitucional. 
de consenso la que lo impide... Y frente a este hecho, poco tiene que ver el procedimiento concreto, como también ocurrió, en otro momento de nuestra historia constitucional, con un procedimiento que influyó en el actual ${ }^{72}$.

\subsection{Reflexiones previas}

Antes de pasar a las propuestas concretas de mejoras, creo que debo reflexionar respecto a la normativa existente, realizando dos advertencias. La primera referida a su sistemática general; la segunda a la terminología.

El Título X de la Constitución española, la normativa que el poder constituyente consideró adecuada para la regulación del procedimiento de reforma, se corresponde con un sistema único, constitucionalmente desarrollado a través de dos vías en razón de la materia. Igual que no consideró la inclusión de cláusulas de eternidad y sí la utilización del referéndum, el constituyente decidió que la reforma se realizase a través de dos procedimientos, sí, pero sólo entendibles poniendo

72 El artículo 125 de la Constitución española de 1931 establecía que, una vez iniciado el procedimiento de reforma a propuesta del Gobierno o de una cuarta parte de los diputados, se necesitaba la aprobación de la misma por dos terceras partes de los mismos durante los primeros cuatro años, bajando posteriormente a la mayoría absoluta después de dicho cuatrienio. Acto seguido se disuelven las Cortes unicamerales y la nueva Asamblea resultante de las elecciones actúa como Cortes constituyentes, decidiendo sobre la reforma y manteniéndose después como asamblea legislativa ordinaria. Pues bien, opina la doctrina que es precisamente dicha disolución la culpable de que cuando se intentase reformar la Constitución en los años 1934 y 1935, la misma fuera imposible, debido al miedo de los parlamentarios a la pérdida del escaño. En palabras del entonces Presidente de la República, «el gran obstáculo para toda la reforma de nuestra Constitución es el artículo 125, defecto magno y múltiple, porque es multiplicador de todos los demás, a los que sirve de refuerzo y parapeto. Sin la reforma de ese artículo no es posible la de los demás, y la de ése es la más difícil de todas. Imponiendo la autodisolución inmediata, al votarse una reforma, coloca a partidos y a diputados en el trance de optar entre el deber y el interés, y éste, para los hombres como para las colectividades, resulta siempre más fuerte, porque incluso se les presenta de buena fe, oscureciendo su conciencia, como el más atrayente, deslumbrador e imperioso de los deberes» (Alcalá Zamora, N., Los defectos de la Constitución de 1931 y tres años de experiencia constitucional, Madrid, Civitas, 1981, págs. 75 y 76). De idéntica opinión Roura Gómez, S. La defensa de la Constitución en la historia constitucional española. Rigidez y control de constitucionalidad en el constitucionalismo histórico español. Madrid: CepC, 1998, págs. 292 o AMÉrigo Alonso y Jeréz Calderón, (o. c., pág. 193). Considero que lo que faltó en aquellos intentos de reforma fue, en primer lugar, el suficiente acuerdo político para proceder a la misma, siguiendo a TORRES DEL Moral en su Constitucionalismo histórico español. Madrid: Атомо, 1991, pág. 201. Malos, muy malos tiempos, corrían ya en una República tan radicalizada para proceder a una reforma de la misma. A mayor abundamiento vid. mis obras La reforma constitucional... o. c., págs. 126-135 y Las Constituciones..., o. c., págs. $392-408$ (sobre todo, págs. 395 y 406). Primero consenso político; después, críticas al procedimiento jurídico-constitucional. Vid. también nota 11. 
en relación el uno con el otro. No se puede entender de otra manera la regulación de la reforma en España. No caben alabanzas ni críticas sin tener clara esta cuestión, ya que las mismas carecerían de sentido. En otras palabras, y yendo al ejemplo concreto, el artículo $168 \mathrm{CE}$ actual sólo se puede entender por la inexistencia de cláusulas de intangibilidad y el consiguiente incremento de los requisitos procedimentales para la consecución de la reforma total o la de los elementos esenciales para nuestra convivencia. Cuestión aparte es que, personalmente abogue por la inclusión de las citadas cláusulas, critique la permisión de la revisión constitucional y considere erróneo el modelo de elección de materias escogido.

En cuanto a la segunda cuestión, la terminológica, creo que uno de los peligros mayores en el ámbito intelectual es el que encierra el lenguaje. A veces, lejos de ser netamente aséptico, puede predisponer indebidamente. Me refiero, en este caso, al uso de los términos, parece que positivos, referidos al procedimiento de reforma del artículo $167 \mathrm{CE}$ como «simple» u «ordinario», frente al procedimiento «complejo» o «extraordinario», entendidos en negativo, referidos al artículo $168 \mathrm{CE}$. Esta literalidad maniquea, demasiado «simple», permítaseme el juego de palabras, nos lleva a pensar en la bondad del uno y en la truculencia del segundo. Discrepo abiertamente. Considero que no existe un momento jurídico político reglado, un proceso más «extraordinario», más «complejo» más «fuera de lo común» que cuando se procede a reformar la Constitución. Por tanto, a nadie debe extrañarle que defienda como positivo aquello que otro sector doctrinal defiende como negativo. Situaciones relevantes para la convivencia requieren de una excepcional regulación que, permitiendo su consecución, por supuesto, reafirmen su importancia a través de requisitos procedimentalmente en consonancia ${ }^{73}$. Vamos, que no es lo mismo redactar un código de circulación que proceder a la reforma de la Ley de Gobierno; ni esta última medida es tan relevante como cambiar las reglas de juego convivenciales. Distinta cuestión es definir el quantum de dicha complejidad, pero a ello iré más adelante.

\subsection{En cuanto a la iniciativa en ambos procedimientos}

Estoy absolutamente de acuerdo en la regulación actual, con las disquisiciones teóricas ya advertidas. Resulta muy acertada la existencia de una pluralidad de sujetos legitimados. También creo que es adecuada la exclusión de la inicia-

${ }^{73}$ Vid. notas 39 y 66. De ahí que destaque del procedimiento del artículo 167 que se dota de varias alternativas para lograr finalmente la reforma iniciada. Todo lo contrario del carácter «consecutivo» que prescribe la literalidad del artículo $168 \mathrm{CE}$, en el que no cabe esa primera opción. 
tiva legislativa popular, como es habitual en el derecho comparado, bien que la teoría política esté en mi contra como reconozco y he expuesto. Como España no es un Estado federal, también apoyo el carácter netamente residual, anecdótico, secundario, de los órganos legislativos autonómicos, en el momento de iniciar el camino de la reforma constitucional ${ }^{74}$.

De igual manera constato la bondad de que se solicite, por un lado, que la iniciativa de reforma sólo la puedan plantear en el Congreso de los Diputados, dos grupos parlamentarios o setenta de sus miembros, frente a la iniciativa legislativa ordinaria que pueden presentar un grupo parlamentario o quince diputados; en la Cámara alta pueden hacer lo propio cincuenta senadores, cuando la iniciativa legislativa ordinaria depende de veinticinco senadores o un grupo parlamentario. Este incremento de los requisitos me parece, insisto, más que adecuado, necesario desde el punto de vista axiológico, valorativo... y supone, para mí, la evidencia de que proceder a una reforma constitucional, desde su inicio, requiere un mínimo consenso.

En cuanto a los límites temporales referidos a la iniciativa de reforma constitucional, regulados en el artículo $169 \mathrm{CE}$, me parecen adecuados, bien que deberían serlo de todo el procedimiento y no sólo referirse al momento iniciático. Considero igualmente útil su regulación, frente a algún autor que considera lo contrario, alegando razones fácticas, por un lado, y de sistematicidad, por otro, argumentos que no comparto, como he destacado en el trascurso de este estudio.

\subsection{Referidas a las previsiones recogidas en el artículo 167}

Insisto de nuevo: las reflexiones que vierto a continuación respecto al artículo citado lo son relacionándolo con la existencia del artículo $168 \mathrm{CE}$, ya que creo que el procedimiento de reforma estudiado no sería adecuado si no existiese, o bien el artículo $168 \mathrm{CE}$, como es el caso, o unas cláusulas de intangibilidad

${ }^{74}$ Vid. nota 22. Respecto a esta cuestión de la consideración de España como Estado autonómico y, por ende, no federal, he escrito en varias ocasiones, la última vez en Vera SANTOS, J. M «Algunas precisiones terminológicas doctrinales, curiosamente olvidadas, referidas a la definición territorial de cualquier Estado (también de España)», en Oliver Araujo, J. (dir.) El futuro territorial del Estado español, Valencia, Tirant lo Blanch, 2014, págs. 157-172. Diferencio, entre otros aspectos, el papel a jugar en éste por los estados federados en la reforma constitucional. Específicamente me he referido a modelos federales en los que la presencia de los estados federados resulta capital en la reforma constitucional, más concretamente al procedimiento de reforma estadounidense, en Vera Santos, J. M. «Los precedentes franceses y estadounidense y su influencia en la rigidez constitucional de la Constitución española de 1812, en Revista de Derecho Político, n. ${ }^{\circ} 83$, vol. 2, 2112, págs. 473-510. 
referidas a los elementos básicos, esenciales, conformadores de la fórmula política, del régimen político, del sustrato básico de nuestra España constitucional.

Efectivamente puedo calificar de positivo este precepto, adjetivado como de «alternativas» para encumbrar con éxito la reforma parcial ordinaria: juego de mayorías o creación de una Comisión Mixta son ejemplo de ello. Tanto del espíritu como de la letra del procedimiento recogido en este precepto, siguiendo el modelo general definido como de mayorías cualificadas ${ }^{75}$, se desprende lo que digo. En fin, que la regulación constitucional de la reforma parcial en España, excluidas las materias a las que se refiere el artículo $168 \mathrm{CE}$, se presenta procedimentalmente como sencilla, abierta. Por tanto, poco tengo que añadir, salvo que se pretenda que esta prescripción se globalice respecto a toda materia. En ese caso soy partidario de un clarísimo incremento de los requisitos procedimentales, desde los propios del momento iniciático hasta el carácter obligatorio de un referéndum que no defiendo pero que se constituiría en «mal menor» si no se estableciesen cláusulas de intangibilidad.

\subsection{Referidas a las previsiones recogidas en el artículo 168}

Paso así a desgranar mis consideraciones sobre artículo 168 CE. Estoy absolutamente en contra de la permisión de la reforma total. Como he dicho, aparte de la confusión indebida del poder constituyente y el poder de reforma, supone una absoluta desvalorización material y formal de la propia Constitución. La indefinición del propio significado de una reforma total, indefinido desde lo cuantitativo y, sobre todo desde lo cualitativo, tampoco aporta mayor consistencia teórica y práctica a la norma.

En lo tocante al ámbito de las materias aludidas por este precepto, casi coincido con la doctrina mayoritaria. Y explico el adverbio utilizado: si bien creo que faltan teóricamente materias muy relevantes (artículos tales como el $53 \mathrm{CE}$ ), no creo que sobren tantas como algún autor critica. En todo caso, el problema viene dado por el sistema de elección de materias, a través de títulos y secciones, método que conlleva la inclusión/exclusión evidente de materias o incluso «submaterias» que efectivamente faltan o sobran. Como he destacado ${ }^{76}$, resulta muy difícil en cualquier caso el establecimiento pacífico, en teoría y práctica, de materias a «superproteger», incluso en el caso de la utilización de cláusulas de intangibilidad concretas, en las cuales encontraríamos otros problemas definitorios similares que deberían dirimirse, en su caso, ante la jurisdicción constitucional.

\footnotetext{
75 Vid. notas 12 y 38 y 73 junto a los argumentos concomitantes.

76 Vid. nota 49.
} 
Como argumento previo respecto al artículo estudiado, defiendo que en ningún caso se puede calificar como cláusula de intangibilidad ¡Es todo lo contrario! El artículo $168 \mathrm{CE}$ establece cómo se puede reformar la totalidad de la propia Constitución y/o determinadas materias, siguiendo esencialmente un procedimiento, con el que se puede discrepar, pero que es asimilable al de otros países, bien que «incrementado», con la utilización del referéndum.

Es cierto que, generalizando, las materias aludidas coinciden con las que se pueden proteger con la citada intangibilidad; Jefatura de Estado, forma territorial del mismo, derechos fundamentales y libertades públicas, sistema democrático... Pero en el caso español, inexplicablemente, vienen referidas para establecer, a continuación, el procedimiento para su reforma, proceso éste costoso pero posible, sin duda alguna.

Respecto al tema procedimental, insisto de nuevo en la idea que, siempre desde la óptica relacional, defiendo la redacción de este artículo, vinculado con el artículo precedente. Creo adecuada la mayoría de dos tercios para aprobar el principio de reforma por unas Cámaras que posteriormente se disuelven, siguiendo un procedimiento denominado de doble legislatura, absolutamente asimilable a otros propios de nuestra historia constitucional y, sobre todo, de la actualidad comparada ${ }^{77}$.

Estas nuevas elecciones legislativas conllevan necesariamente -siempre que la iniciada reforma recaiga respecto a una cuestión, no tanto doctrinalmente relevante sino, sobre todo, polémica en la práctica política-, una discusión del electorado al respecto, algo que considero lógico, aparte de adecuado. Lo anterior conlleva que la composición de las nuevas Cámaras pueda o no variar, teniendo en cuenta, efectivamente, no sólo la acción del gobierno anterior sino la postura de cada partido referida a la materia a reformar.

Entiendo la ratificación por parte de las nuevas Cámaras del principio de reforma. Parece lógico que así sea, para pasar a continuación a la articulación concreta del mismo. Si ni siquiera se ratificase, debido a una composición política diferente de las recién elegidas Cámaras, decaería la iniciativa de reforma. Mi postura favorable no quita la crítica a que cada una de las Cámaras solicite una mayoría diferente en este momento refrendatario, abogando por una reforma de los reglamentos parlamentarios.

Considero adecuado que el texto articulado requiera de idéntica mayoría de dos tercios en cada una de las Cámaras, símbolo de un consenso cierto respecto a la propuesta estudiada. En caso de problemas en la aprobación soy contrario a la interpretación de algunos autores respecto a la utilización, por analogía, de una especie de comisión de conciliación intercameral a imagen de la prevista en el apartado primero del artículo $167 \mathrm{CE}$.

77 Vid. notas 12 y 59. 
En cuanto al carácter obligado del referéndum, caigo en una aparente contradicción, siendo, como soy, contrario a su uso con carácter general. En el caso que nos ocupa, debido a la regulación concreta referida, resulta necesario para evitar la posible tendencia asamblearia de unas segundas Cámaras que podrían obviar, extralimitándose en sus funciones, el principio de reforma aprobado por las primeras. Y es que el referéndum referido en el apartado último del artículo 168 supone la espita de seguridad para asegurar que, aunque los concretice, la segunda Legislatura respeta los acuerdos adoptados por la primera. Esta es la única fórmula de velar por que, efectivamente, se lleve a la práctica el sistema establecido por la Constitución de que sean dos Cortes consecutivas las encargadas de definir la reforma ${ }^{78}$.

El ejemplo belga, con la necesaria participación del Monarca para acordar con las nuevas Cámaras electas el cumplimiento del principio aprobado, no parece extrapolable a nuestro sistema ${ }^{79}$. Quizás debería ser una competencia del Tribunal Constitucional... Así lo propongo en el caso de que se optase por un modelo similar al del artículo 168 actual.

\section{PROPUESTAS QUE SE PLANTEAN}

Desde el respeto más absoluto a opiniones que difieran de las que a continuación expongo, siguiendo los argumentos antes vistos, la presencia institucional de los procedimientos defendidos en nuestro texto constitucional y la práctica $\operatorname{comparada}^{80}$, voy a intentar sistematizar mi postura al respecto, bien que antes de entrar en cuestiones materiales, quisiera recordar una cuestión previa: como ya he expuesto anteriormente, no me cabe duda alguna que cualquier reforma a la que me refiero en este epígrafe debe realizarse ex artículo $168 \mathrm{CE}^{81}$. Lo contrario sería obviar el deseo del constituyente español y romper la dicotomía doctrinal y fáctica existente entre poder constituyente y poderes constituidos.

78 Los ya citados BILBAO, Rey y VidAL (o. c., pág. 294) aluden a una «vinculación temática» entre el principio aprobado en la primera Legislatura y un resultado final que sí podría afectar a preceptos conexos. Incido con esta cita de nuevo en la problemática concreta de la «desvinculación» entre las decisiones de una y otra Legislatura y su posible control, para evitar asamblearismos. Las soluciones se exponen en el punto 3.2 de esta mismo apartado.

79 Vid. nota 59.

80 Vid. Vera Santos La reforma... o. c., págs. 171-179. Aunque no soy partidario de tanta auto cita, como ya he expuesto, las propuestas que realizo se basan necesariamente en los argumentos previos que vengo realizando sobre la cuestión.

${ }^{81} \mathrm{Vid}$. nota 58 respecto a la crítica al planteamiento teórico del «doble procedimiento de reforma». 
Veamos ya las propuestas que defiendo.

1. Creo que sería más adecuada la existencia de un único procedimiento de reforma, bien siguiendo el modelo del artículo 167, es decir, simple incremento de las garantías procedimentales, según el sistema denominado «de mayoría cualificada», bien optando por el ejemplo del artículo 168, posibilitando por tanto la reforma constitucional a partir de un procedimiento de doble legislatura.

No abogo por establecer un método de reforma que se base en la elección de órganos ad hoc ni tampoco por el sistema italiano de doble lectura en una sola legislatura. El primero lo creo poco operativo y puede producir mucho «ruido en el sistema»; el otro puede resultar viable si se conjuga con mayores requerimientos procesales en la toma de decisiones, lo que nos llevaría a un modelo, mixto sí, pero muy similar al del artículo 167.

2. Independientemente del procedimiento que al final se adopte, creo importante el establecimiento de cláusulas de intangibilidad. No voy a repetir ahora la argumentación vertida ya en este artículo y otras aportaciones anteriores $^{82}$. Creo en la bondad jurídica y política de las mismas. Es cierto que pueden ser superadas por el deseo del pueblo soberano como poder constituyente originario, pero también destaca mientras eso ocurre, su función directiva, axiológica, de principios, según una idea democrática de Constitución que he defendido y seguiré defendiendo. Principio de supremacía constitucional, principio de legalidad y de sometimiento de la Administración y del poder político a las normas, declaración y garantía de los derechos fundamentales y libertades públicas, así como la separación de poderes que garanticen lo anterior, resultan ingredientes necesarios, fundamentos últimos para el logro de la libertad individual y colectiva y de un ordenamiento democrático que las proteja.

A partir de estas premisas, deben establecerse intangibilidades en dicho sentido: ni la existencia misma de España, la soberanía popular o su consideración como Estado de derecho, democrático y social pueden someterse a cotidiana almoneda.

La Jefatura de Estado o su forma territorial, conforman de la misma manera cuestiones inamovibles, no por cuestiones principiales como las anteriores, sino porque su cambio supondría una reforma total de la Constitución, competencia que, como he dicho antes, trasciende con mucho el poder constituido de reforma constitucional, entrando de lleno en un poder constituyente que no admite, por definición, límites materiales ni tampoco formales ${ }^{83}$.

${ }^{82}$ Vid. notas 42 y 50 y siguientes.

83 Belda Pérez-Pedrero (o. c., págs. 269-273) alude como posibles cláusulas pétreas a los derechos fundamentales y libertades públicas, junto a la separación de poderes y el principio de supremacía constitucional ex artículo 16 de la Declaración de Derechos del Hombre y del Ciuda- 
Por los motivos ya expuestos, referidos a la diferencia entre poder constituyente y poder constituido, discrepo en que la protección de los principios esenciales antes dicha se pueda realizar eludiendo las cláusulas de intangibilidad, utilizando el referéndum obligatorio, tal y como he defendido sin mucho éxito por otra parte ${ }^{84}$. Y es que la necesaria pervivencia del «núcleo esencial», de la «superconstitución», es lo que permite la pervivencia de la misma y, en consecuencia, que podamos hablar de reforma constitucional y no de supresión de la $\operatorname{misma}^{85}$.

3. He aludido hasta ahora a dos cuestiones: la bondad de la existencia de un único procedimiento y, en segundo lugar, a que en el mismo, sea el que sea, se incluyan cláusulas de intangibilidad. En este tercer epígrafe voy a discernir los pros y los contras de las diferentes opciones procesales, valorando las que considero más adecuadas.

3.1 Si se sigue el sistema de mayoría cualificada del artículo 167 CE, aparte de su complementación con cláusulas de intangibilidad, como ocurre en los Estados democráticos de referencia, creo que deben incrementarse las exigencias procesales del meritado precepto, aumentando las mayorías solicitadas tanto en el inicio del procedimiento como en la postrera tramitación, pasando, por ejemplo, de los tres quintos a los dos tercios. Aunque puedan permitirse comisiones de conciliación, éstas no deberían desdibujar el necesario consenso y deberían respetar las mayorías cualificadas establecidas. La reforma constitucional, el cambio de Constitución de cualquier materia, excluidas sean las intangibles, debe principiarse y finalizarse con un acuerdo político relevante, importante ${ }^{86}$.

dano; la soberanía popular, los valores recogidos en el artículo 1.1, la dignidad de la persona, el Título II... aparecen derivados de la propia Constitución. Califica de materias «concordantes pero reformables» (págs. 284-287) los excesos del Título Preliminar, los órganos constitucionales (siempre que se respeten las funciones esenciales) y la reforma de las normas de reforma. Respecto a la postura de dicho autor referida a la Jefatura del Estado vid. la más que sugerente monografía Belda, PÉrez-Pedrero, E. «Que le falta a la Monarquía española para estar plenamente racionalizada. Valladolid: Fundación Aranzadi Lex nova/ Thompson Reuters, 2015. Vid. nota 50 y la opinión de Fernández De Casadevante respecto a la inclusión dentro de estas cláusulas de otros contenidos meritados.

${ }^{84}$ Me refiero a las conclusiones definitivas recogidas respecto a la reforma constitucional en el excelente estudio citado en nota 2, Pautas para una reforma..., o. c., págs. 125-128.

85 Tomo los términos entrecomillados de García-Atance y García De Mora, M. V. «Veinticinco años de la institución de la reforma constitucional», en Revista de Derecho Político, n. ${ }^{\circ}$ 58-59, 2003-2004, págs. 401-421 (en concreto 413-414), siguiendo a De Vergottini y Barile. Destaca la relevancia de lograr la estabilidad de dichos límites materiales, a pesar de que nuestra Constitución caiga en la ya citada auto desvalorización material permitiendo su propia reforma total.

${ }^{86}$ Vid. nota 8 y la diferencia entre democracia «de» y «en» la Constitución. 
No me parece necesario el uso del referéndum pero, en todo caso, podría convocarse con una mayoría de diputados y/o senadores más elevada.

3.2 Si se siguiera el modelo general basado en la aprobación por una doble Legislatura, podríamos encontrarnos con dos posibilidades ${ }^{87}$, según el rol asignado a cada una de ellas.

A) Si atendemos al modelo del artículo 168, las primeras Cortes sólo aprueban el principio de reforma; las segundas, ratifican el mismo y aprueban un texto articulado ${ }^{88}$. En este caso, existe un riesgo cierto de que estas últimas desnaturalicen el principio de reforma aprobado por la primera Legislatura, de ahí que se prevea en nuestra Constitución una cláusula de seguridad para que esto no pase: un referéndum que, de esta manera, entorpece enormemente el proceso, agravándolo innecesariamente.

De optarse por esta vía, soy partidario de -aparte incluso de rebajar de dos tercios a tres quintos las mayorías cualificadas exigidas, debido a la necesidad de ser aprobadas por dos Legislaturas consecutivas-, soy defensor, digo, de que sea el Tribunal Constitucional el que garantice la hilazón, la consecutividad argumental entre el principio de reforma aprobado por las primeras Cámaras y el texto articulado definitivo que se pretende aprobar por las segundas. Para ello apostaría por un procedimiento similar al establecido respecto a la declaración de constitucionalidad de los Tratados internacionales recogido en el artículo 78 de la Ley orgánica del Tribunal Constitucional.

Dicha declaración del supremo intérprete de la Constitución se debería realizar antes del sometimiento del texto articulado a su aprobación definitiva por la segunda Legislatura, para evitar un siempre mal utilizado choque de legitimidades; además debería realizarse de oficio y el Tribunal Constitucional debería pedir informes no sólo a las Cámaras, que están inmersas en la tramitación de la reforma, sino al menos también al Gobierno y al Consejo de Estado, como supremo órgano consultivo.

B) También abogando por este sistema de dos Legislaturas, se podría optar por cambiar las competencias de cada una de ellas, de tal forma que se evitara los posibles excesos asamblearios por parte de la segunda, elemento que distorsionaba el apartado A) antes citado. Así, si las primeras Cámaras, con las mayo-

${ }^{87}$ Sigo de nuevo, con matizaciones, la diferenciación del papel de cada Legislatura según los ejemplos foráneos (once países europeos) que asumen un proceso de reforma con intervención de dos Legislaturas, a los que alude el Informe del Consejo de Estado tantas veces citado (págs. 248-249).

88 «(..) la primera legislatura declara la necesidad de la reforma (...) La doctrina belga entiende que la función de la primera legislatura es simplemente la de habilitar como constituyente a la que ha de venir después» (Ibídem) 
rías cualificadas correspondientes ${ }^{89}$, redactasen un texto articulado, algo no viable en la actualidad ${ }^{90}$, las nuevas Cámaras sólo podrían votar la totalidad del mismo, aprobando la reforma o no ${ }^{91}$. De esta manera se imposibilitaría la conculcación del deseo del constituyente de que se aprobase la reforma por dos Legislaturas consecutivas, impidiendo que las últimas fuesen las híper protagonistas. Sería pues innecesaria una llamada al Tribunal Constitucional por esta causa y el uso del referéndum, como en el caso anterior, sería en todo caso potestativo y creo que a partir de una mayoría de diputados y senadores superior a la prevista en el artículo $167 \mathrm{CE}$.

Concluyo recordando la utilidad de la reforma, consensuada previamente y siempre acorde con las disquisiciones teóricas y, sobre todo, con la realidad política y social. Así la razón no producirá monstruos... De nosotros depende. De la doctrina, sí; de nuestros políticos, también... Pero, sobre todo, de una ciudadanía concienciada a la que también, como Diógenes, sigo buscando con mi candil.

Title:

The reform of the the Spanish constitutional reform procedure.

\section{Summary:}

Introduction: the housekeeper is evaluating the possibility of refurbishing the kitchen. 1. Title X of the Spanish Constitution of 1978. 1.1. Constitutional reform initiative and its temporal limits (arts. 166 and 169). 1.2. The reform procedure under article 167. 1.3. The reform procedure under article 168. 2. Possible and desirable reforms or how

${ }^{89}$ Me refiero, como antes he destacado al aludir al modelo A), a que las mayorías cualificadas solicitadas podrían ser rebajadas.

90 Vera Santos, «De la elaboración de propuestas...», o. c., pág. 768. Sigo el citado Informe del Consejo de Estado (pág. 250) en el que se explicita que la regulación actual impide la elaboración de propuestas articuladas de reforma tanto a los órganos dotados de iniciativa como a las primeras Cortes que se disuelven.

91 «En todos los demás países mencionados [excluye a Bélgica, Grecia y Luxemburgo, que siguen el modelo de doble Legislatura explicado en el apartado A), por lo que se refiere a los otros ocho Estados restantes, tales como Dinamarca, Países Bajos o Suecia], por el contrario, es la primera legislatura la que establece el contenido de la reforma, limitándose el poder de la segunda al de aceptarlo o rechazarlo en conjunto, pero sin introducir en él modificación alguna (...)» (Ibídem, pág. 249). No parece demasiado original la idea que defiendo. 
the sleep of reason can produce monsters, although it should not. 2.1. Previous reflections. 2.2. Regarding the initiative in both procedures. 2.3. Regarding the considerations set out in article 167.2. 2.4. Regarding the stipulations set out in article 168. 3. Provided proposals.

\title{
Resumen:
}

El autor realiza un estudio previo de la regulación constitucional referida a la reforma constitucional en España, para posteriormente establecer pautas que puedan mejorar el procedimiento de reforma. Para ello basa sus propuestas en dos principios: 1. La inclusión de cláusulas de intangibilidad, independientemente del procedimiento a seguir. 2. Establecimiento de un único procedimiento de reforma constitucional, aprovechando la inercia de la actual regulación constitucional, bien siguiendo el sistema de mayoría cualificada (similar al establecido actualmente en el artículo 167 CE), bien el de doble Legislatura (ejemplificado en las previsiones prescritas en el artículo 168 $\mathrm{CE}$ ), resolviendo las disfunciones que ambos procedimientos podrían atesorar, simplificando los mismos.

\begin{abstract}
:
The author conducts a previous study on constitutional regulation concerning the Spanish constitutional reform, in order subsequently to establish guidelines to improve the reform procedure. To this end he bases his proposals in two principles: 1 . The inclusion of intangibility clauses, regardless of the procedure to be followed. 2. The establishment of a single constitutional reform procedure, seizing the inertia of the current constitutional regulation, following either the qualified-majority system (similar to the one currently established in article 167) or the double legislature one (exemplified in article 168 stipulations), and resolving and simplifying in both cases the malfunctions that both procedures could present.
\end{abstract}

\section{Palabras clave:}

reforma de la Constitución, cláusulas de intangibilidad, procedimiento de reforma constitucional por mayoría cualificada; procedimiento de reforma constitucional por doble legislatura.

\section{Keywords:}

constitutional reform; intangibility clauses; constitutional reform procedure by qualified-majority; constitutional reform procedure by double legislature. 